\title{
The ubiquity of uncertainty: a scoping review on how undergraduate health professions' students engage with uncertainty
}

\author{
Jenny Moffett ${ }^{1}$ (D) . Jennifer Hammond ${ }^{2} \cdot$ Paul Murphy $^{1} \cdot$ Teresa Pawlikowska $^{1}$
}

Received: 12 November 2020 / Accepted: 11 January 2021 / Published online: 1 March 2021

(C) The Author(s) 2021

\begin{abstract}
Although the evidence base around uncertainty and education has expanded in recent years, a lack of clarity around conceptual terms and a heterogeneity of study designs means that this landscape remains indistinct. This scoping review explores how undergraduate health professions' students learn to engage with uncertainty related to their academic practice. To our knowledge, this is the first scoping review which examines teaching and learning related to uncertainty across multiple health professions. The scoping review is underpinned by the five-stage framework of (Arksey and O'Malley in Scoping studies: Towards a methodological framework International Journal of Social Research Methodology 8(1) 19-32, 2005). We searched MEDLINE, Embase, PsychINFO, ISI Web of Science, and CINAHL and hand-searched selected health professions' education journals. The search strategy yielded a total of 5,017 articles, of which 97 were included in the final review. Four major themes were identified: "Learners' interactions with uncertainty"; "Factors that influence learner experiences"; "Educational outcomes"; and, "Teaching and learning approaches". Our findings highlight that uncertainty is a ubiquitous concern in health professions' education, with students experiencing different forms of uncertainty at many stages of their training. These experiences are influenced by both individual and systemrelated factors. Formal teaching strategies that directly support learning around uncertainty were infrequent, and included arts-based teaching, and clinical case presentations. Students also met with uncertainty indirectly through problem-based learning, clinical teaching, humanities teaching, simulation, team-based learning, small group learning, tactical games, online discussion of anatomy topics, and virtual patients. Reflection and reflective practice are also mentioned as strategies within the literature.
\end{abstract}

Keywords Ambiguity $\cdot$ Learning $\cdot$ Teaching $\cdot$ Uncertainty $\cdot$ Undergraduate

Jenny Moffett

jennymoffett@rcsi.com

1 RCSI Health Professions' Education Centre, 123 St Stephen's Green, Dublin, Ireland

2 School of Veterinary Medicine, College of Medical, Veterinary and Life Sciences, University of Glasgow, Glasgow, UK 


\section{Introduction}

Health professionals regularly encounter uncertainty in their work, experiencing "a subjective perception of not knowing what to think or what to do" (Sommers and Launer 2014). Indeed, it is accepted that uncertainty is "normal, understandable, and to be expected in professional practice" (Coles 2013). When confronted with complex or ambiguous situations, individuals react in different ways, often framed in terms of their cognitive, emotional and behavioural responses (Mushtaq et al. 2011; Strout et al. 2018). These differences, and the capacity of health professionals to manage uncertainty overall, are often referred to as "uncertainty tolerance." Studies, largely in medicine, have found that professionals' capacity to manage uncertainty is important with respect to their career choices (Merrill et al. 1994; Cranley et al. 2012; Caulfield et al. 2014), attitudes to patients (Merrill et al. 1994; Wayne et al. 2011), clinical decision-making skills (Merrill et al. 1994; Strout et al. 2018), and exposure to work-related stress (Logan and Scott 1996; Bovier and Perneger 2007; Lally and Cantillon 2014; Iannello et al. 2017; Simpkin et al. 2018). Furthermore, a professional's capacity to work with uncertainty has been linked to positive outcomes for others, e.g., greater patient satisfaction (Johnson et al. 1988; Gordon et al. 2000) and decreased medical errors (Light 1979; Fielding 1999). A recent review by Strout and colleagues (2018) highlighted a strong, consistent association between health professionals' uncertainty tolerance, and their patients' emotional well-being. This growing evidence base has encouraged the addition of uncertainty management competences to many regulatory professional frameworks (AMRC 2009; Benson et al. 2015; GMC 2018; RCVS 2018).

Considering this increasing research interest, relatively less attention has been paid to how health professions' learners build this capacity to work with uncertainty. Existing studies point to a long-standing balancing act between the overarching human preference for certainty and the uncertain nature of real-world patient care (Fox 1957; Atkinson 1984; Katz 1984; Beresford 1991; Han et al. 2011; Simpkin and Schwartzstein 2016). Authors suggest that we have consistently failed to bridge the gap between the two, labeling training for uncertainty as medical education's "most elusive ideal" (Ludmerer 1999). This contributes to an educational climate which "rewards those who give correct answers, and often denigrates learners who admit uncertainty" (Wray and Loo 2015).

It has also been argued that health professions' education may have come adrift with regards to preparing learners for the "messiness and unpredictability" of professional practice (Wilkinson 2017). Wear (2009) hypothesises that the "rapid shift... to a technologydriven, competency-oriented environment" may mean that learners have less opportunity to develop "responsiveness to an evolving human situation in a clinical context." Indeed, could our modern curricula, "bloated with required lectures and courses, with insufficient time for independent thought and elective study", lie at the heart of the problem? (Ludmerer 1999).

Authors have recommended specific ways to facilitate learning around uncertainty, from humanities teaching, small group approaches, and simulation (Hazel et al. 2013; Bleakley and Marshall 2013; Wald et al. 2015; Ofri 2017; White and Williams 2017; Tonelli and Upshur 2019), through to faculty development (Domen 2016; George and Lowe 2019). Taken as a whole, however, little is known about how health professions' programmes "intentionally and systematically" teach students to manage uncertainty (Ledford et al. 2015). This leaves educators in a position where they are asked to support learning around uncertainty, but with little clear advice on how best to do this (Cooke and Lemay 2017; Ofri 2017; White and Williams 2017). 
Although the evidence base around uncertainty and education has expanded in recent years, a lack of clarity around conceptual terms and a heterogeneity of study designs means that this landscape remains indistinct, replete with "fuzzy" boundaries (Grenier et al. 2005; Hillen et al. 2017; Strout et al. 2018). This hinders educators' ability to prepare health professions' learners to work with the uncertainty inherent in their day-to-day work. The authors considered that the existing literature could be usefully "mapped", making what we know so far in relation to uncertainty and education more accessible. Our aim was to explore how learners from a range of different health professions begin to learn about uncertainty within the context of their education. As our interest extended across multiple professions, we decided to focus on findings related to undergraduate health professions' learners as these may be more broadly comparable. We chose a scoping review approach to provide an overview of this emergent evidence base. This was considered an appropriate methodology which could help us unravel what research exists, and what characteristics or factors are important when considering uncertainty in health professions' education (Munn et al. 2018). To our knowledge, this is the first scoping review which examines teaching and learning related to uncertainty across multiple health professions.

\section{Methods}

We followed the scoping review framework described by Arksey and Malley (2005), and incorporated guidance by Peters and colleagues (2015). The five steps of the framework were: (1) identifying the research question, (2) identifying relevant studies, (3) selection of relevant studies, (4) charting the data, and (5) collating, summarising and reporting the results. In addition, we used the Preferred Reporting Items for Systematic reviews and Meta-Analyses extension for Scoping Reviews (PRISMA-ScR) to guide reporting of the study (Tricco et al. 2018) (Appendix 1).

Stage 1 Identifying the review question

Following a pilot search, we decided to focus on how undergraduate health professions' learners both experience and respond to uncertain situations. The final wording for the research question was: "How do undergraduate health professions' students learn to engage with uncertainty related to their academic practice?" We adopted a broad definition which framed uncertainty as a "subjective perception of ignorance that is experienced by health professionals in differing ways and degrees, motivates action, and elicits a variety of psychological responses" (adapted from Han and colleagues, 2011). Our focus on undergraduate learners took into consideration the different models and approaches to health professions' education which exist (Wijnen-Meijer et al. 2013). Thus, we were interested in studies which related to students enrolled on health professions-specific, college-level courses which would lead to registration to practise in their chosen profession. Finally, we chose the verb "engage", so as to capture both learners' experiences of, and responses to, uncertainty, as these were both deemed of interest.

Stage 2 Identifying relevant studies

We devised the search strategy in consultation with an academic librarian through an iterative process using both keywords and Medical Subject Headings (MeSH) terms. Due to conceptual overlap between uncertainty and ambiguity, which was evident in the literature and within our pilot search, both terms were included in the search (Grenier et al. 2005; Rosen et al. 2014; Hillen et al. 2017). 
We searched MEDLINE, Embase, PsychINFO, ISI Web of Science, and CINAHL (sample strategy included as Appendix 2). In addition, we carried out a hand search of 14 health professions' education journals (Appendix 3), and completed a backward citation search of all articles which met the review criteria. We limited all strands of the search to studies published from January 1, 1950 until September 14, 2020.

Stage 3 Selection of relevant studies

We used EndNote X7.8 (Thomson Reuters, USA) to import and organise the citations of articles yielded from the search strategy. Initially, articles were grouped according to their source, and duplicate citations were removed. Researchers JM and JH independently reviewed a group of 50 studies in tranches to pilot the initial eligibility criteria, and make any necessary refinements. Studies were included in this review on the basis of an agreed set of inclusion and exclusion criteria (Table 1). JM and JH independently screened titles and abstracts of the studies to identify those eligible for full-text review. A third researcher (TP) was consulted on disagreements until consensus was attained (Fig. 1). All studies deemed relevant were submitted for full-text screening. Again JM and $\mathrm{JH}$ independently screened studies, with TP facilitating consensus.

Stage 4Charting the data
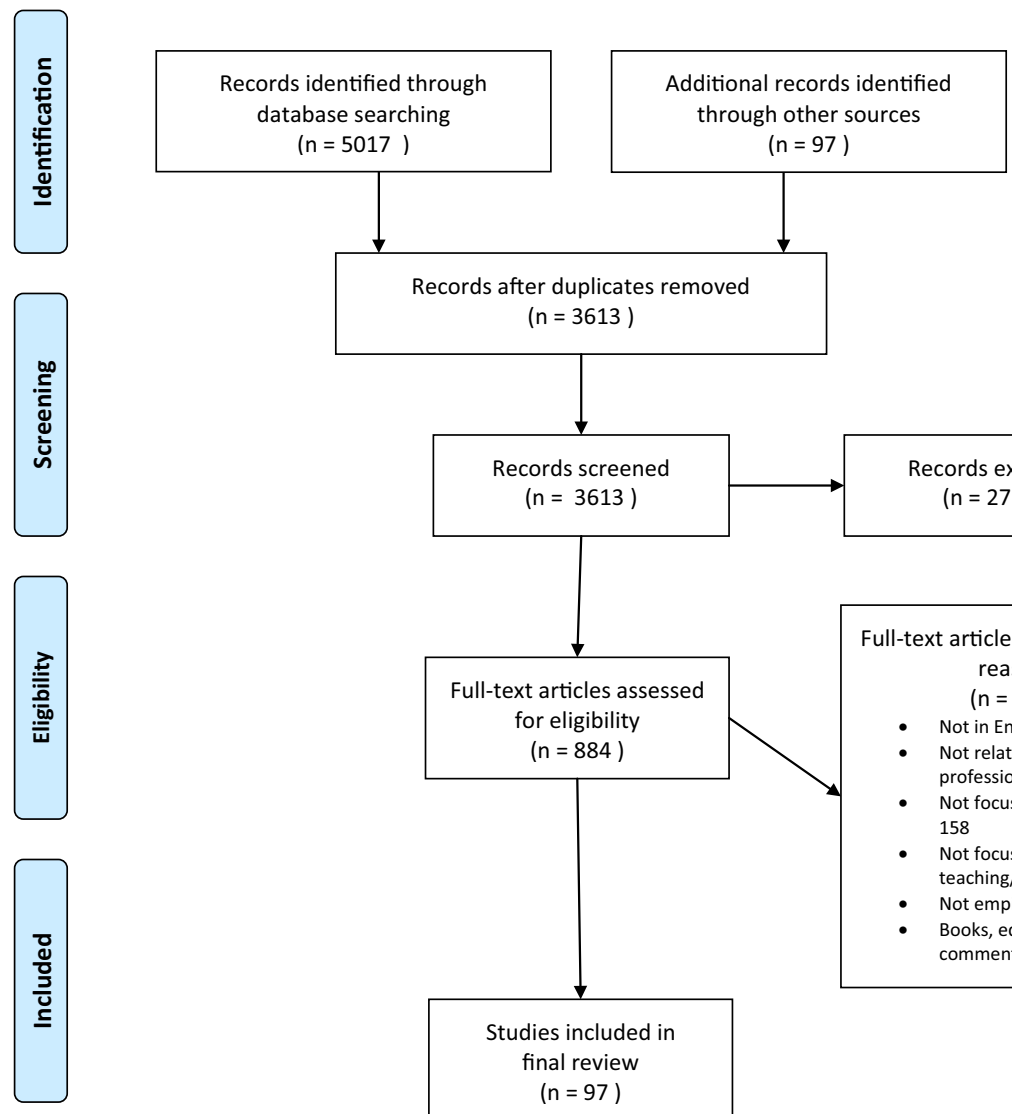

Records after duplicates removed $(n=3613)$
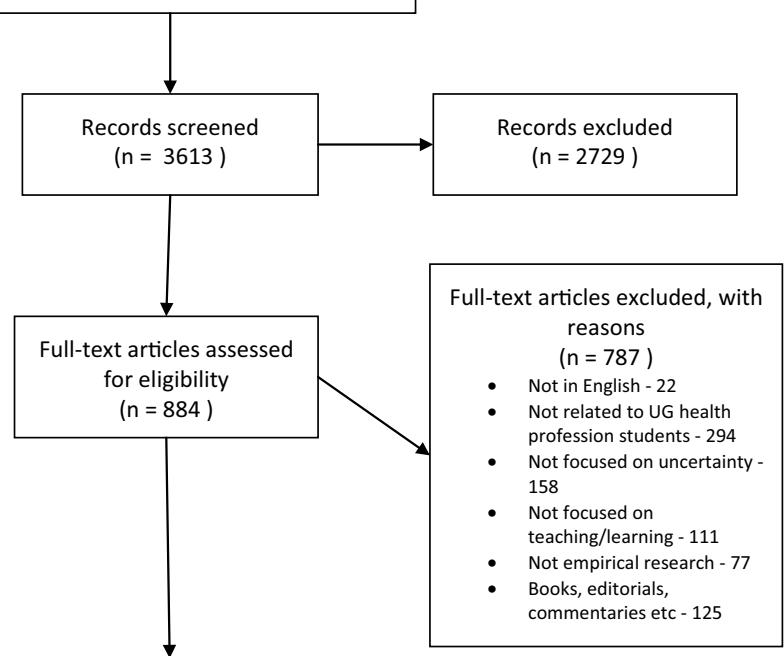

Studies included in final review $(n=97)$

Fig. 1 PRISMA ScR 
Table 1 The ubiquity of uncertainty: a scoping review on how undergraduate health professions' students engage with uncertainty: Inclusion and exclusion criteria

\begin{tabular}{ll}
\hline Inclusion criteria & Exclusion criteria \\
\hline $\begin{array}{l}\text { Articles were included in this scoping review if they: } \\
\text { Were published in English }\end{array}$ & $\begin{array}{c}\text { Articles were excluded from this scoping review } \\
\text { if they: } \\
\text { Related to undergraduate health professions' students } \\
\text { Related to postgraduate education or continuing } \\
\text { professional development }\end{array}$ \\
$\begin{array}{l}\text { veterinary medicine, physical therapy and/or physi- } \\
\text { otherapy, pharmacy students) }\end{array}$ & $\begin{array}{c}\text { Focused on teaching and learning from the } \\
\text { perspective of the educator or patient, or from } \\
\text { bocuader paradigms e.g., educational development } \\
\text { vidual's professional practice }\end{array}$ \\
$\begin{array}{c}\text { Focused on teaching and learning as reported by } \\
\text { student rather than other stakeholders }\end{array}$ & $\begin{array}{c}\text { editorials, letters, opinion papers, or unpublished } \\
\text { theses }\end{array}$ \\
$\begin{array}{c}\text { Described empirical research (i.e., represented a peer- } \\
\text { reviewed article with overt data collection) }\end{array}$ & \\
\hline
\end{tabular}

Data extraction followed an iterative process, and a template was used to extract the following information: publication details (authors, publishing year, title of journal and paper), country of origin, study design, study population, research outcome(s), type and description of intervention, if any, as well as key findings that related to the research question. We used a combination of Microsoft Excel and Forms (Microsoft, USA) to extract the data, with the characteristics of the full-text articles extracted independently by JM and JH. Studies were excluded at this stage if they did not meet eligibility criteria. Discrepancies were solved through re-reading and discussing studies in consultation with TP.

Stage 5 Collating, summarising and reporting the results

We used a narrative approach to thematically synthesise the data (Braun and Clarke 2013); JM and JH identified initial themes within the studies. These were shared, mapped and discussed iteratively, which helped visualisation of the data and recognition of connections between themes. The third researcher (TP) addressed any discrepancies to ensure consensus was reached.

\section{Results}

\section{Characteristics of included studies}

The search strategy yielded a total of 5,017 articles, of which 97 articles were included in the final review (Fig. 1).

Of these studies, half had been published within the last five years $(50 \%, n=48)$, with the USA the most frequently reported location $(35 \%, n=34)$, followed by the UK $(20 \%$, $\mathrm{n}=19)$, and Canada $(11 \%, \mathrm{n}=11)$. Studies described both uniprofessional $(90 \%, \mathrm{n}=87)$ and multiprofessional $(10 \%, \mathrm{n}=10)$ student cohorts. The most commonly represented students were medical $(65 \%, n=63)$, followed by nursing $(25 \%, n=24)$. Studies were more likely to describe qualitative research $(57 \%, \mathrm{n}=55)$, than quantitative $(32 \%, \mathrm{n}=31)$, or 
mixed method approaches $(11 \%, \mathrm{n}=11)$. A summary of the final study characteristics is presented in Table 2 .

\section{Identified themes and sub-themes}

Four major themes were identified: "Learners' interactions with uncertainty"; "Factors that influence learner experiences"; "Educational outcomes"; and, "Teaching and learning approaches".

\section{Learners' interactions with uncertainty}

\section{Types of learners}

A wide variety of health professions' learners meet uncertainty within the context of their undergraduate studies. The vast majority of studies reported on cohorts of medical and nursing students; however, experiences of uncertainty were also recorded within midwifery, physiotherapy, veterinary, dentistry and pharmacy student cohorts (Finnerty and Pope 2005; Friary et al. 2018; Hancock et al. 2017; Hazel et al. 2013; Schéle et al. 2011; Rowan et al. 2008; Porteous and Machin 2018; Nevalainen et al. 2012; Kashbour et al. 2019; Brondani and Donnelly 2020; Jowsey et al. 2020). Studies included learners at all stages of their undergraduate training.

\section{Types of uncertainty}

Learners' experiences of uncertainty, could be categorised as: (i) uncertainty related to the practice of healthcare itself (Ali et al. 2017; Nixon et al. 2014; Sobal and Deforge 1991; Carr et al. 2001; Lingard et al. 2003a; Ganesh and Ganesh 2010; Markey et al. 2018; Weurlander et al. 2019); (ii) uncertainty related to the educational process (Biley and Smith 1999; Dodgson et al. 2018; Mc Carthy et al. 2018; Hazel et al. 2013; Leh 2011; Stone et al. 2015; Maudsley et al. 2008; Gonzalo et al. 2020); and (iii) uncertainty related to the learner's self (Ganesh and Ganesh 2010; Toivonen et al. 2017; Lingard et al. 2003a; Schéle et al. 2011; Vae et al. 2018; Young-Brice et al. 2018; Handwerker 2018; Nevalainen et al. 2010, 2012; Huijer et al. 2000; Weurlander et al. 2019). Uncertainty emerged when learners experienced differences between themselves and others (Ion et al. 2015; Watkins et al. 2011; Lewinson et al. 2018; Curtis 2014; Martinez and Lo 2008; Markey et al. 2019), unfamiliar situations, or issues lacking easily distinguishable solutions (Ion et al. 2015; Watkins et al. 2011; Lewinson et al. 2018; Matchim and Raetong 2018; Warner et al. 2001; Toivonen et al. 2017; Bassett et al. 2015). Common places where this happened were at transitions (e.g., entry into undergraduate studies, movement into, and between, clinical placements) (Porteous and Machin 2018; McCarthy et al., 2018; Ingvarsson et al. 2019; Teunissen and Westerman 2011), and in specific environments such as problem-based learning (Maudsley et al. 2008; Landeen et al. 2013; Rowan et al. 2008), and clinical settings (Krupat et al. 2011; Leh 2011; McCarthy et al. 2018; Kashbour et al. 2019; Mol et al. 2019; Koufidis et al. 2020). Several studies commented on how the types of uncertainty that learners experienced, and their concerns around these, evolved as they progressed through their education (Sobal and Deforge 1991; Kristiansson et al. 2014). Finally, the uncertainties faced by students in the context of the global coronavirus pandemic began to emerge in studies published in 2020 (Brondani and Donnelly 2020; Ramos-Morcillo et al. 2020). 


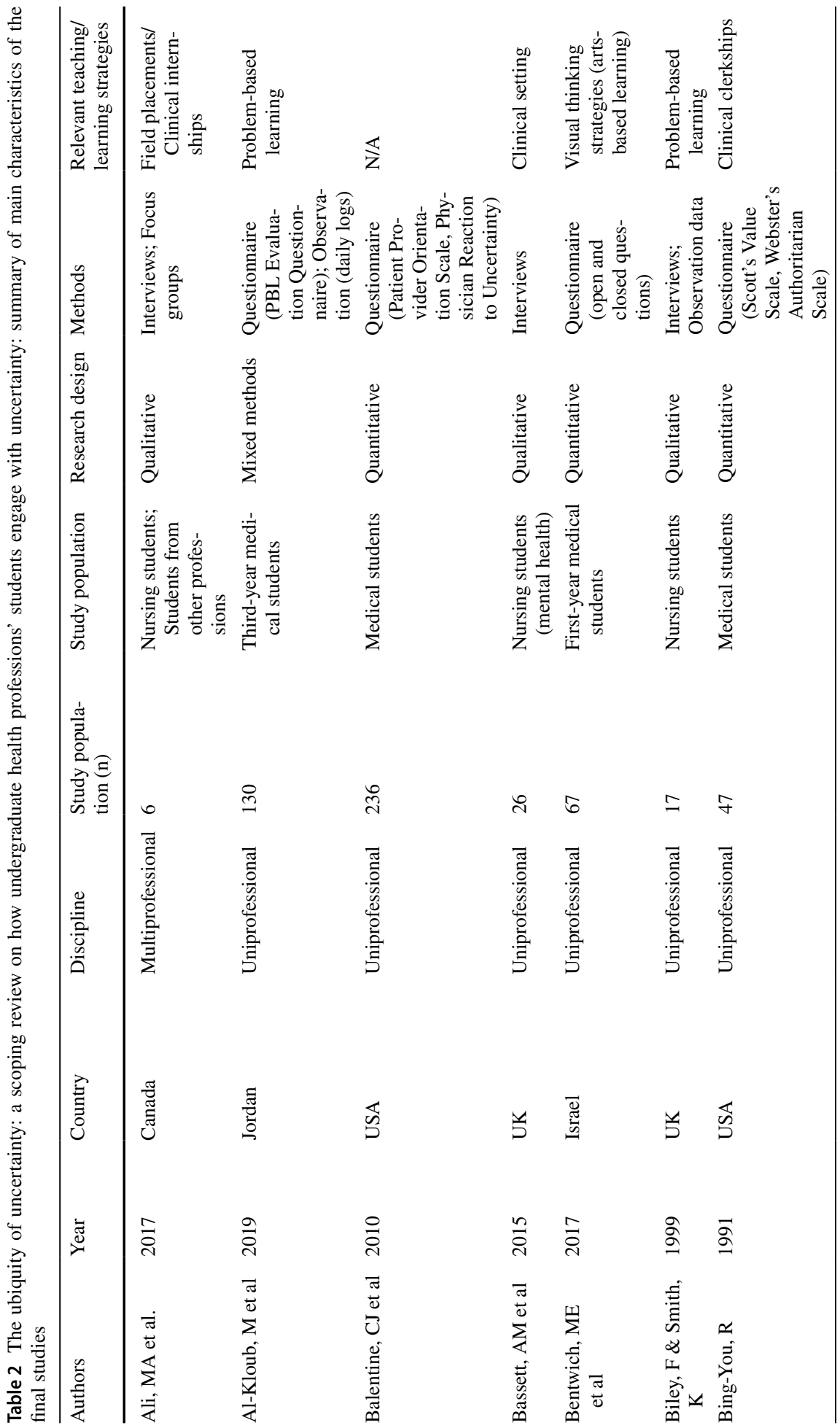




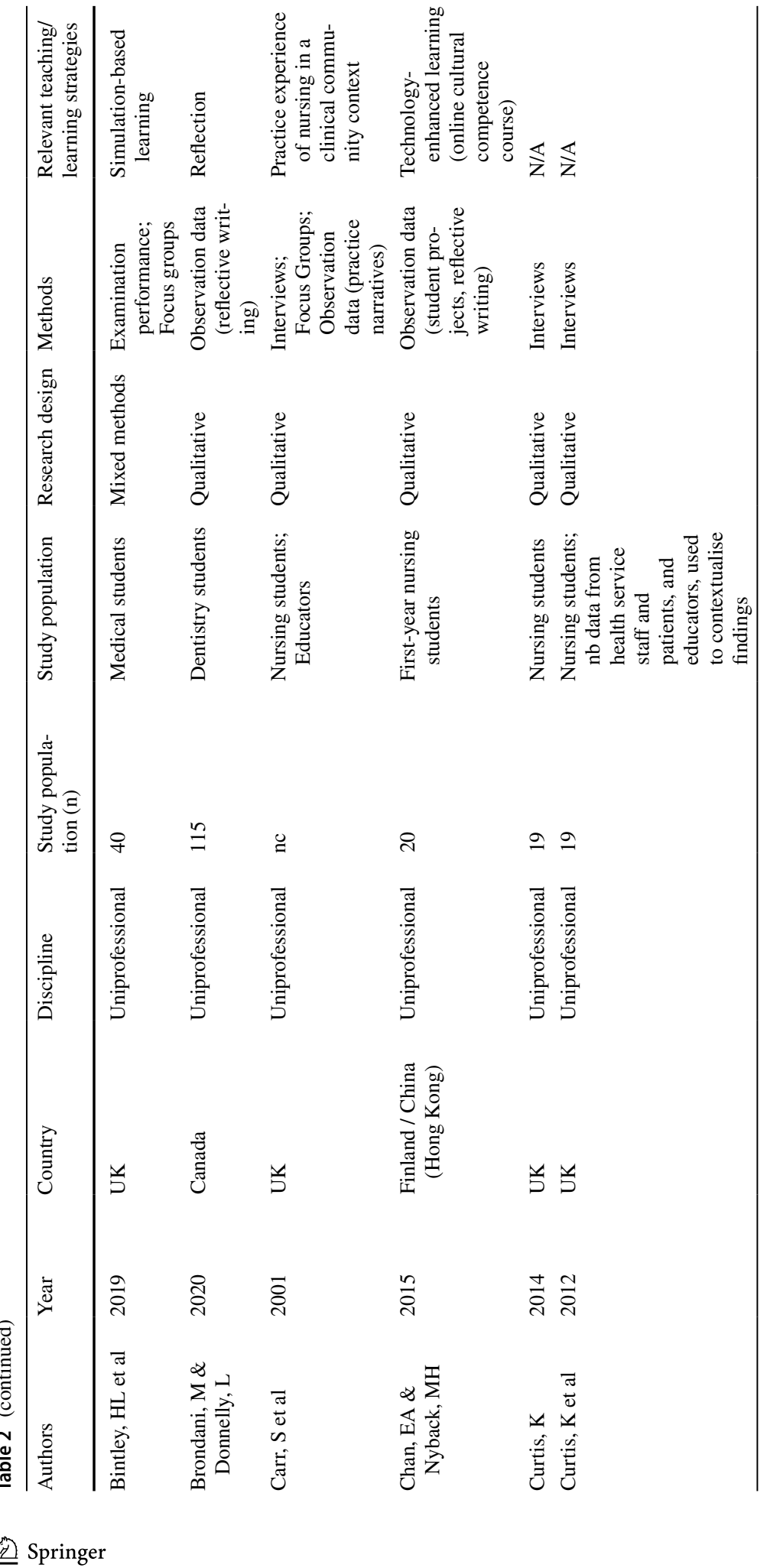




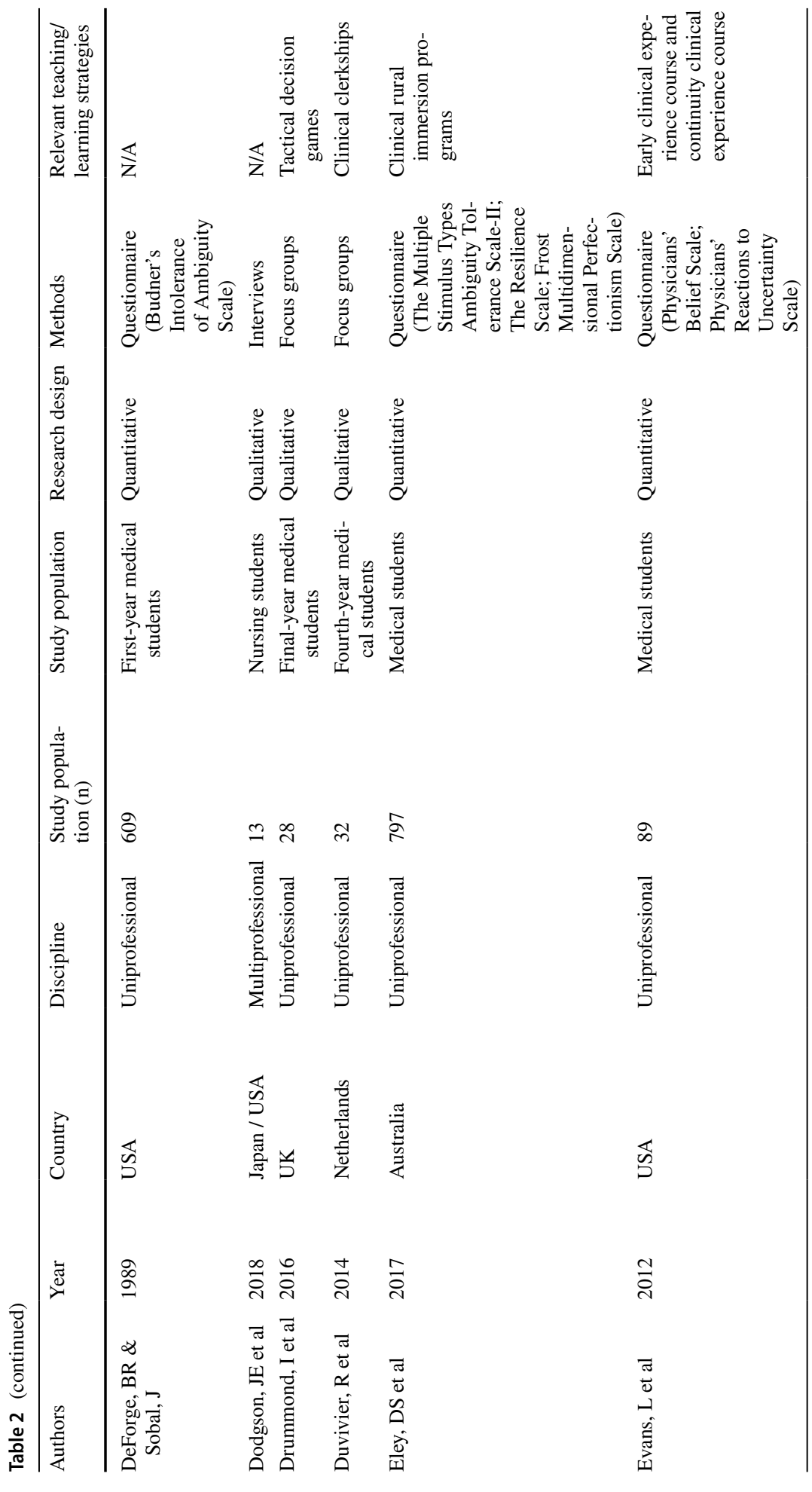




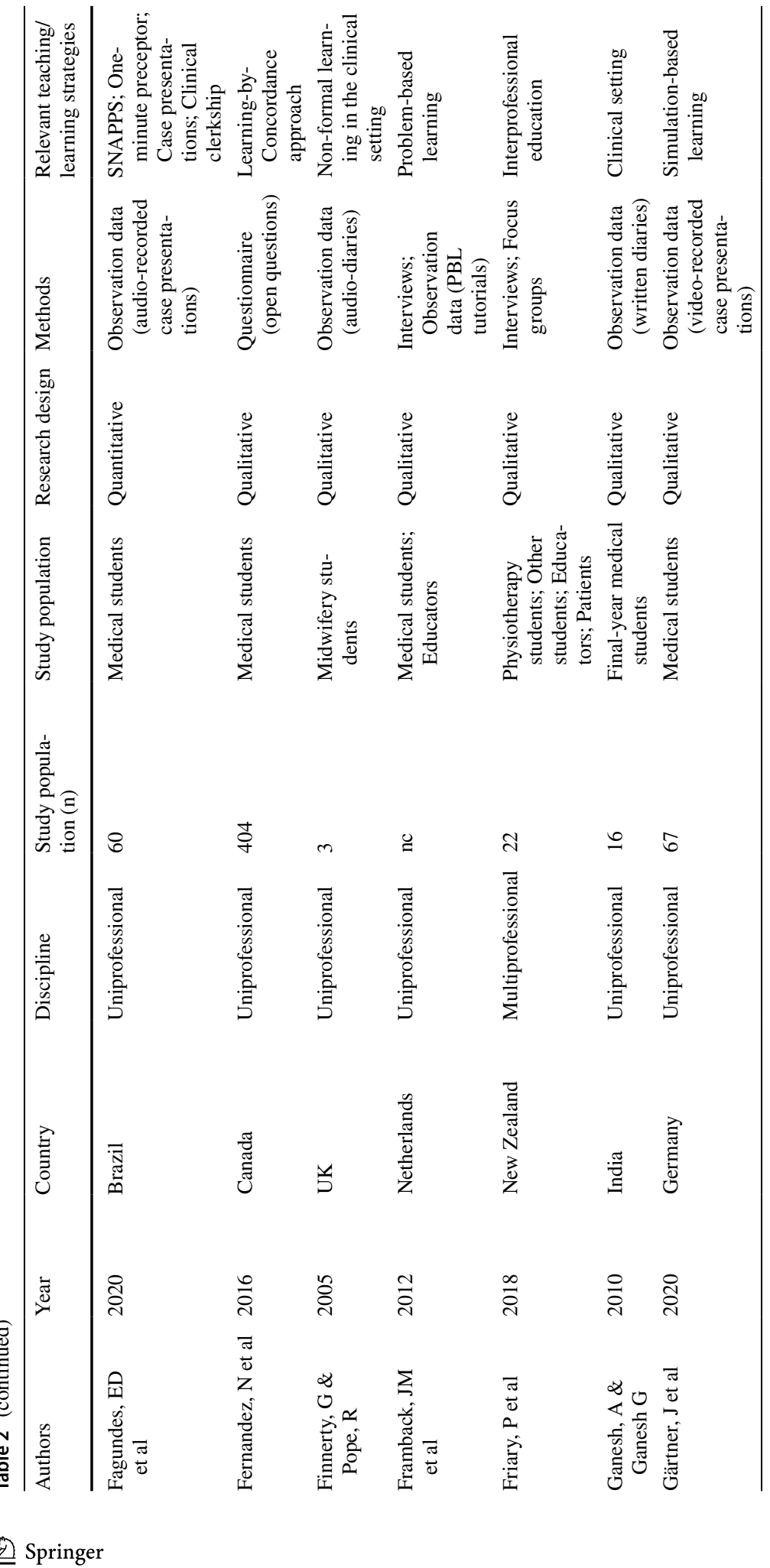




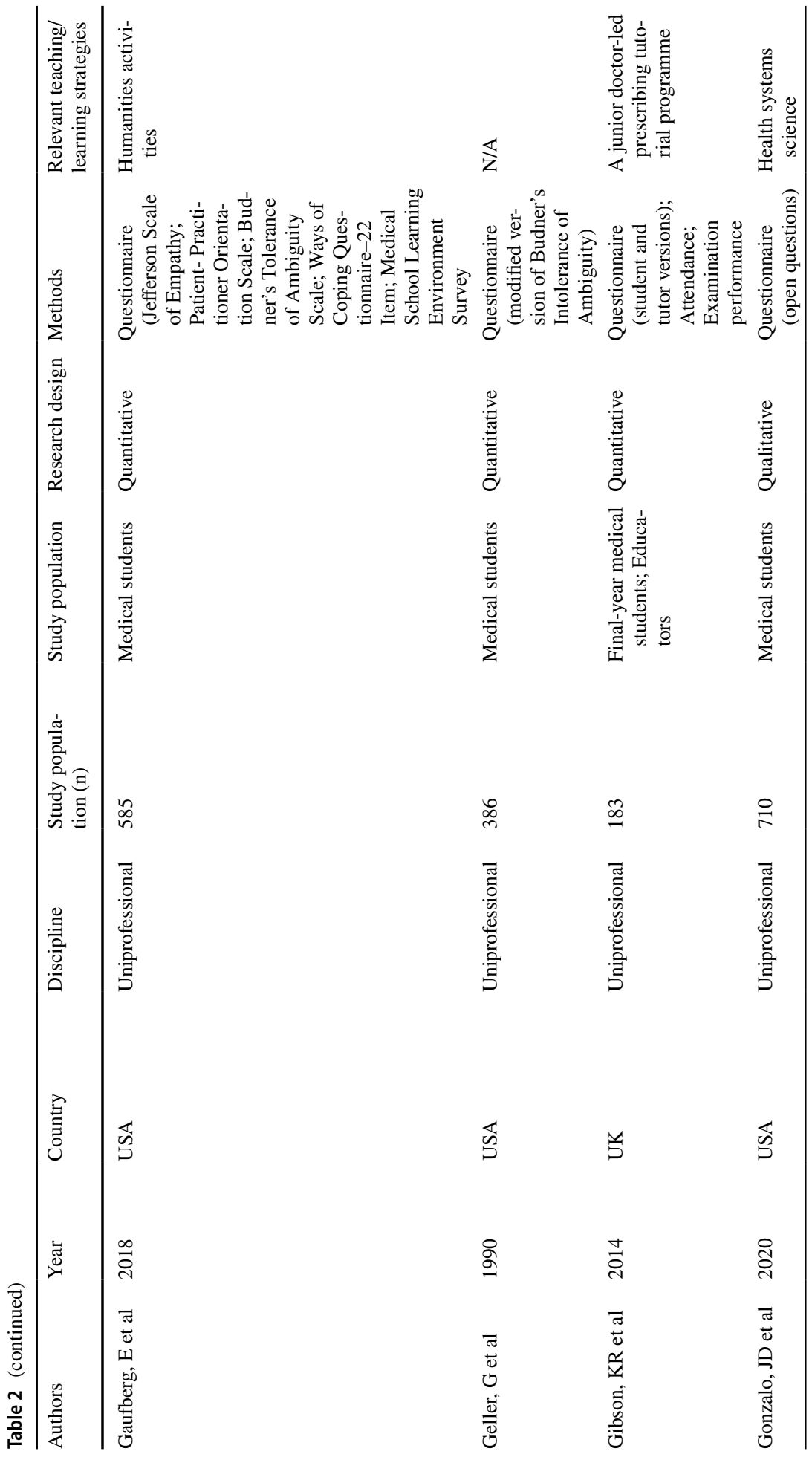




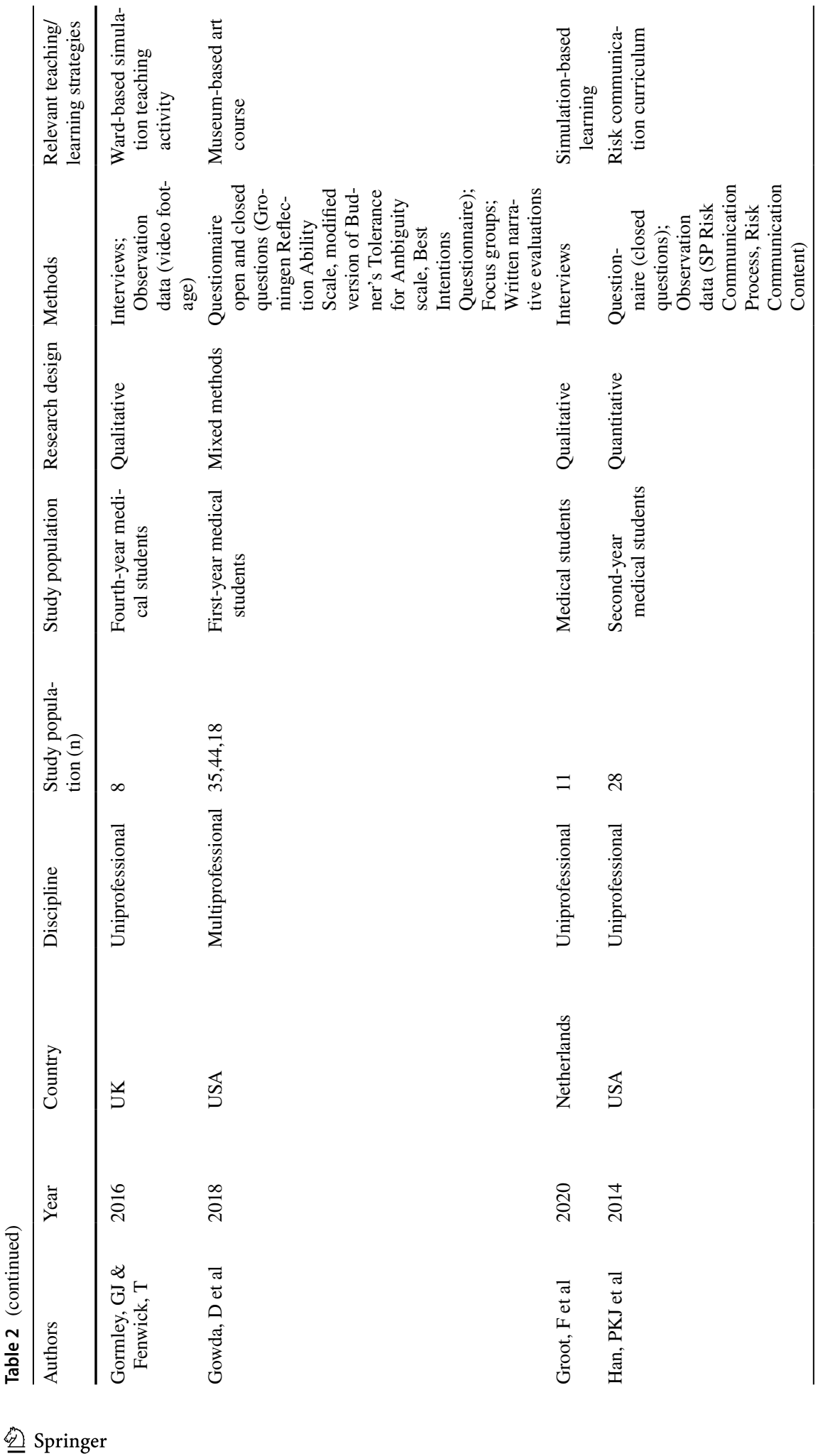




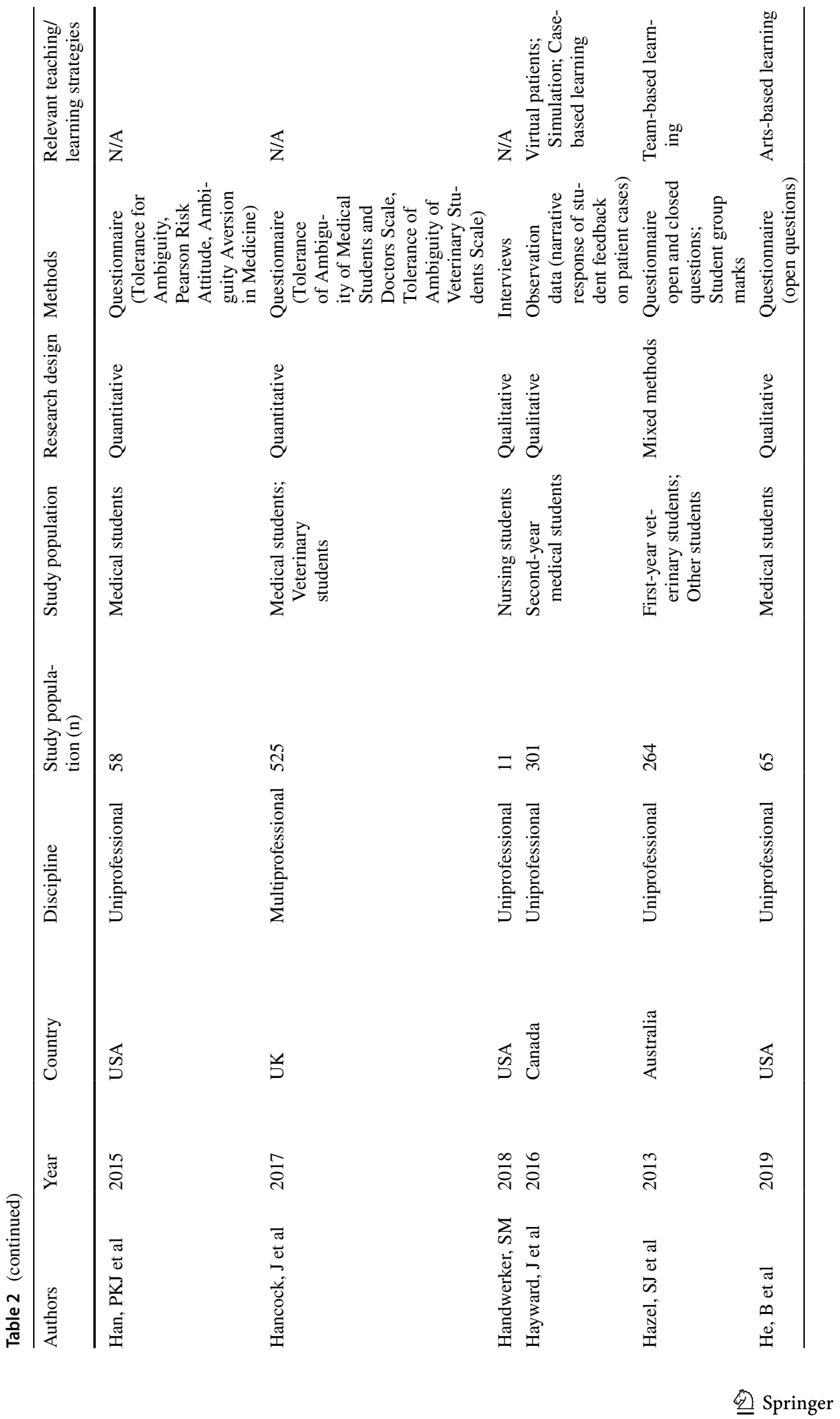




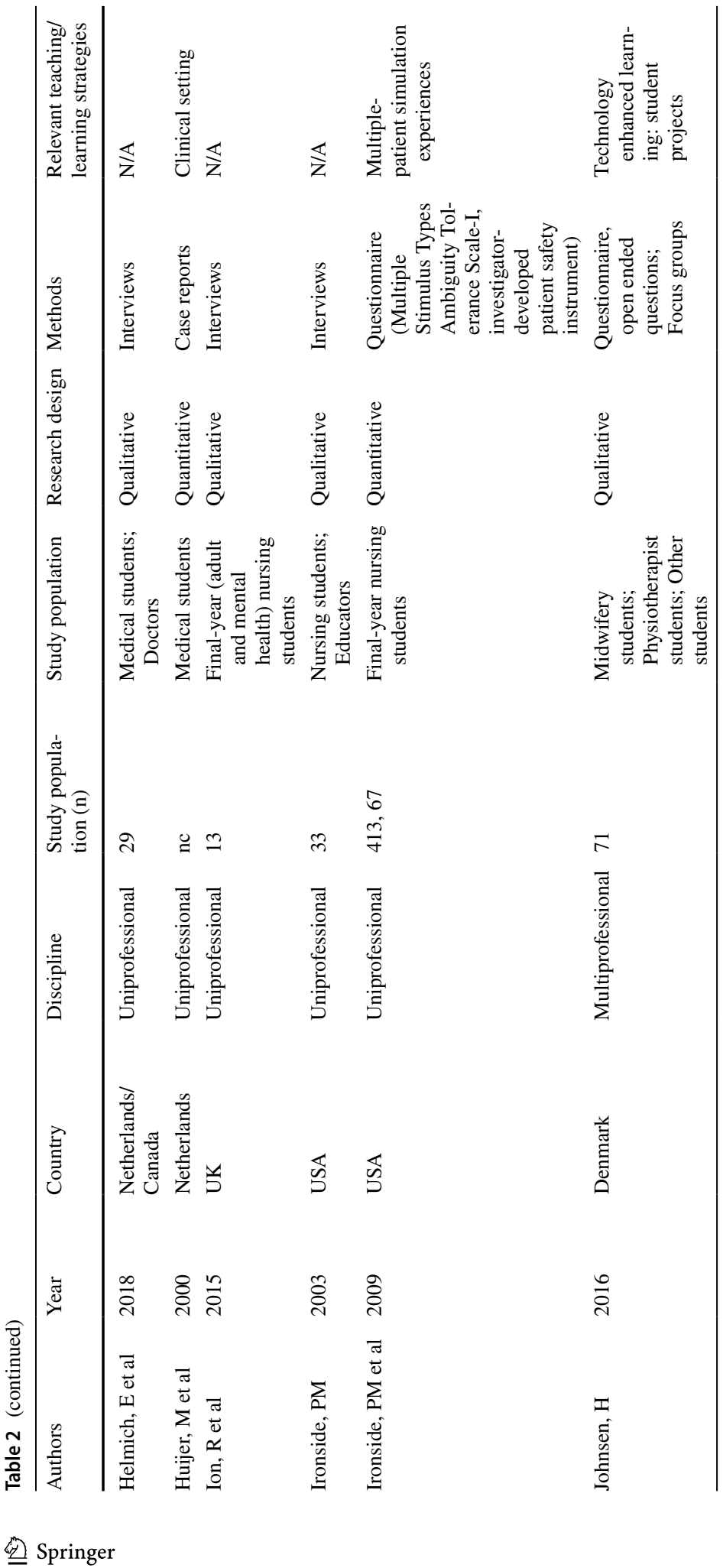




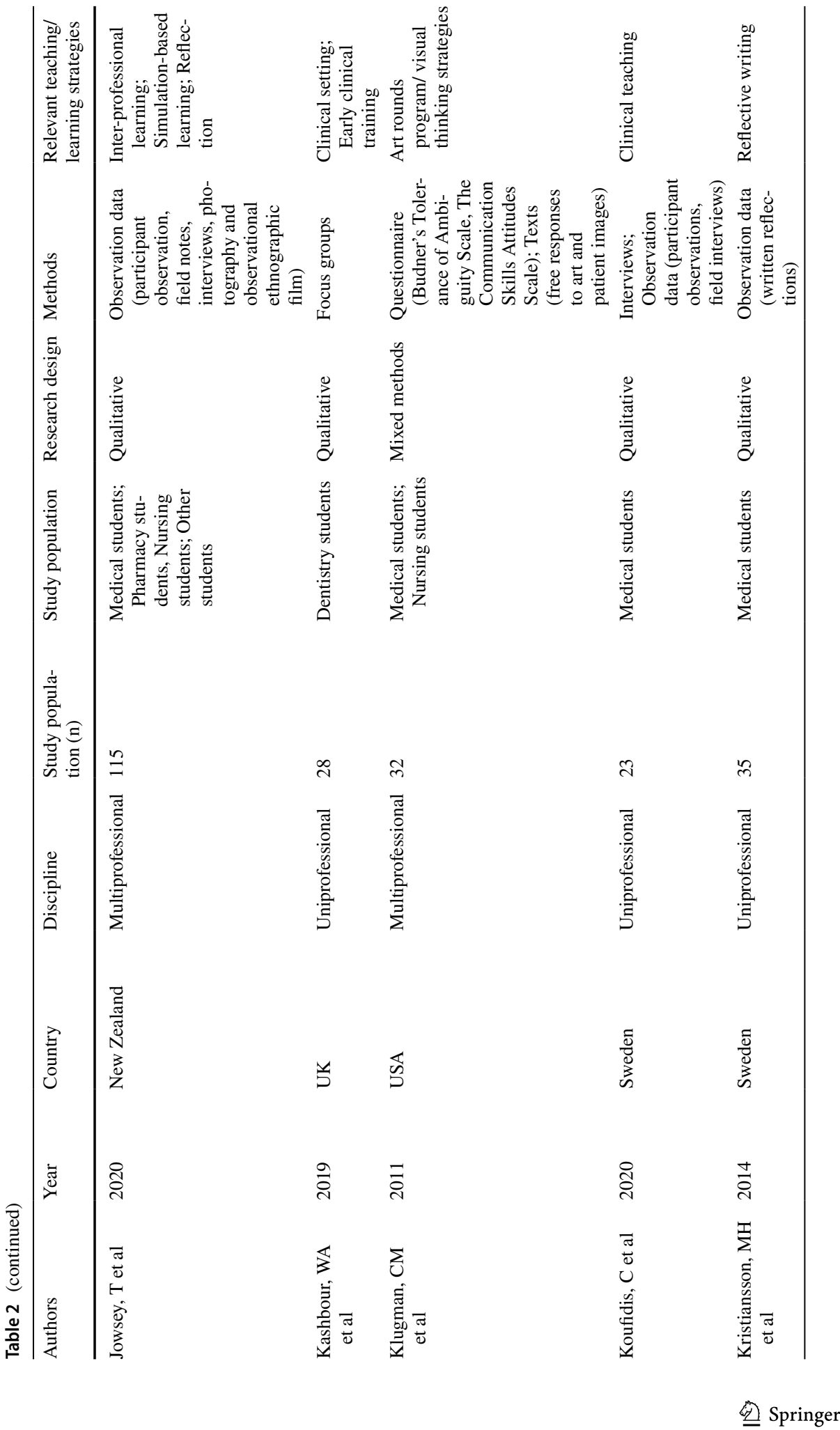




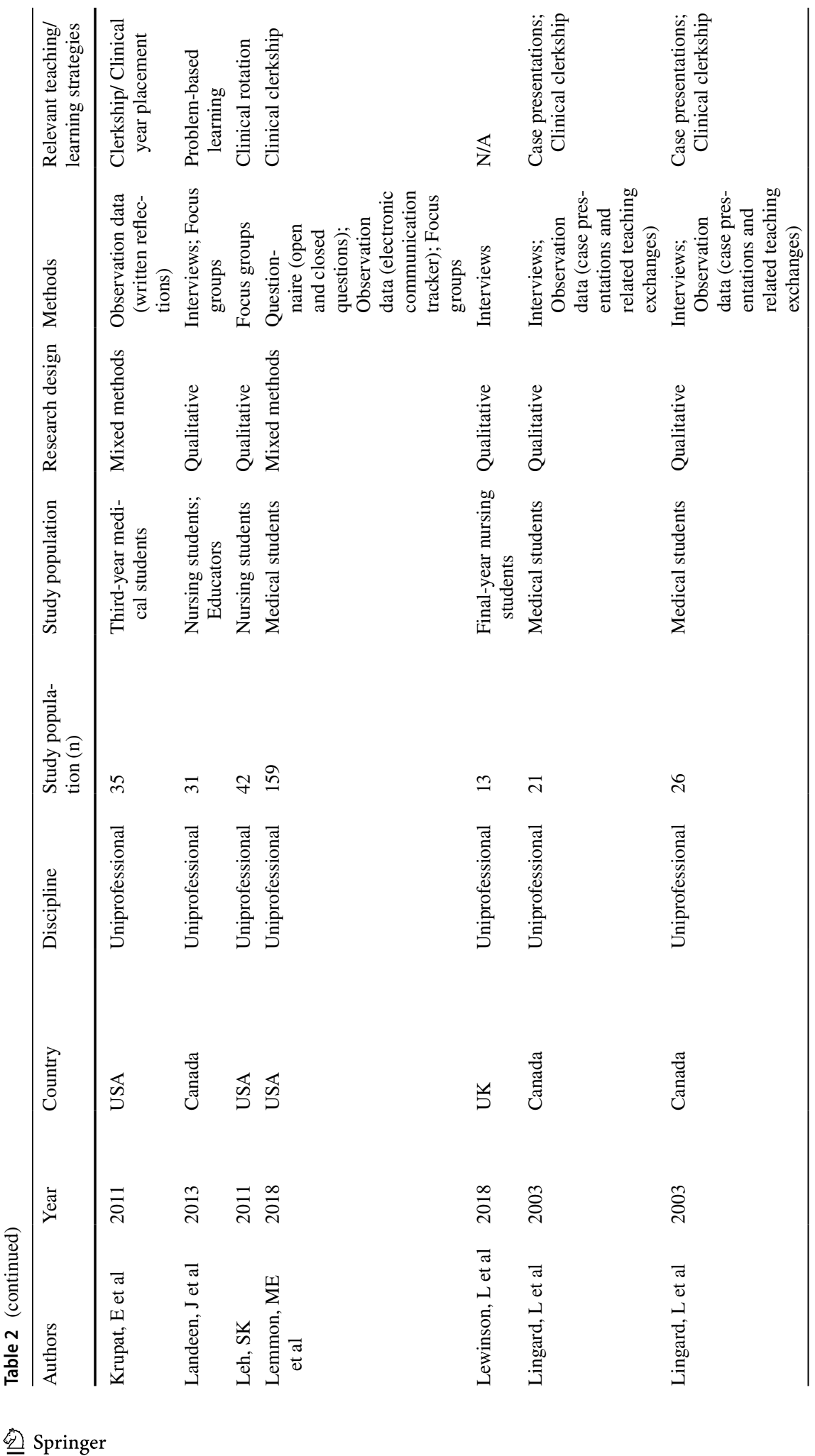




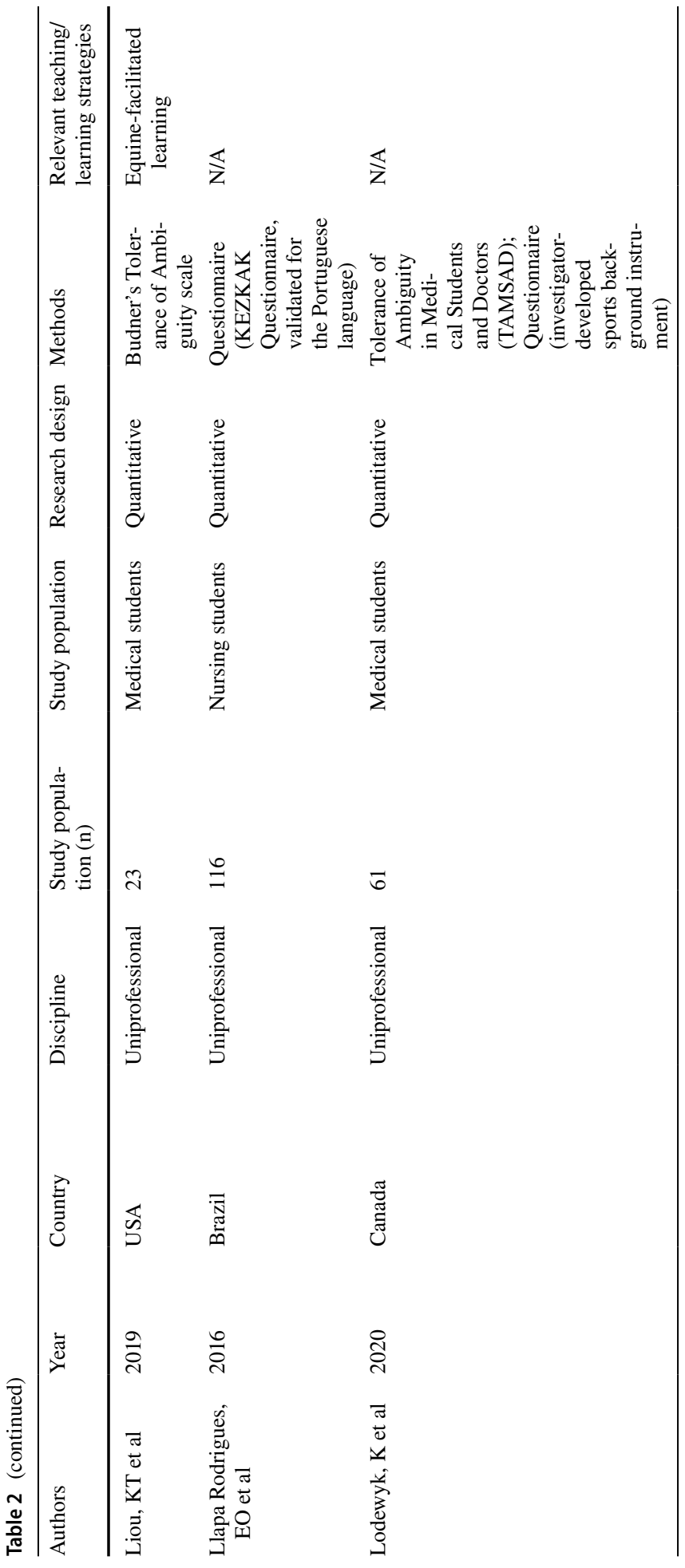




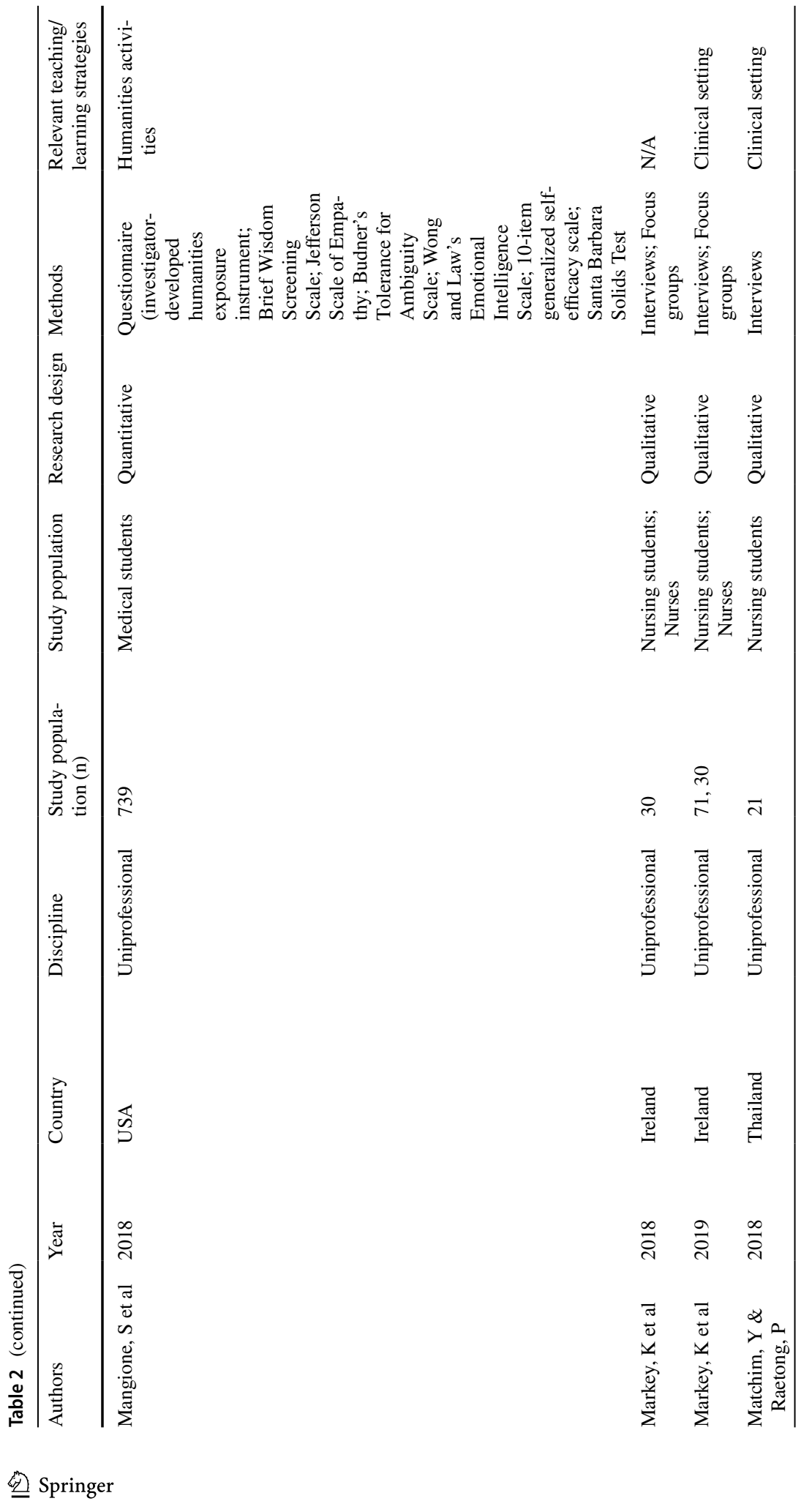




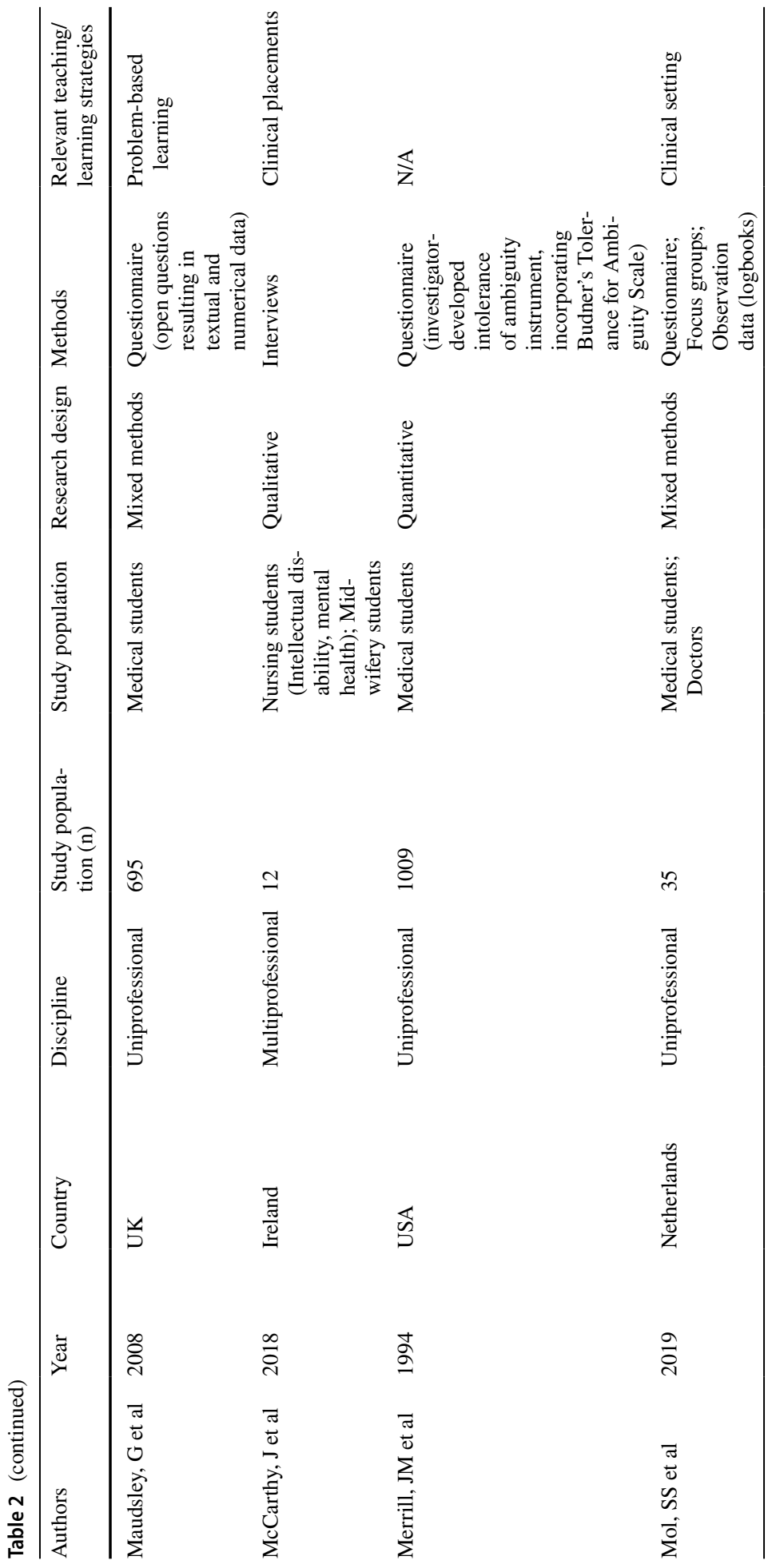




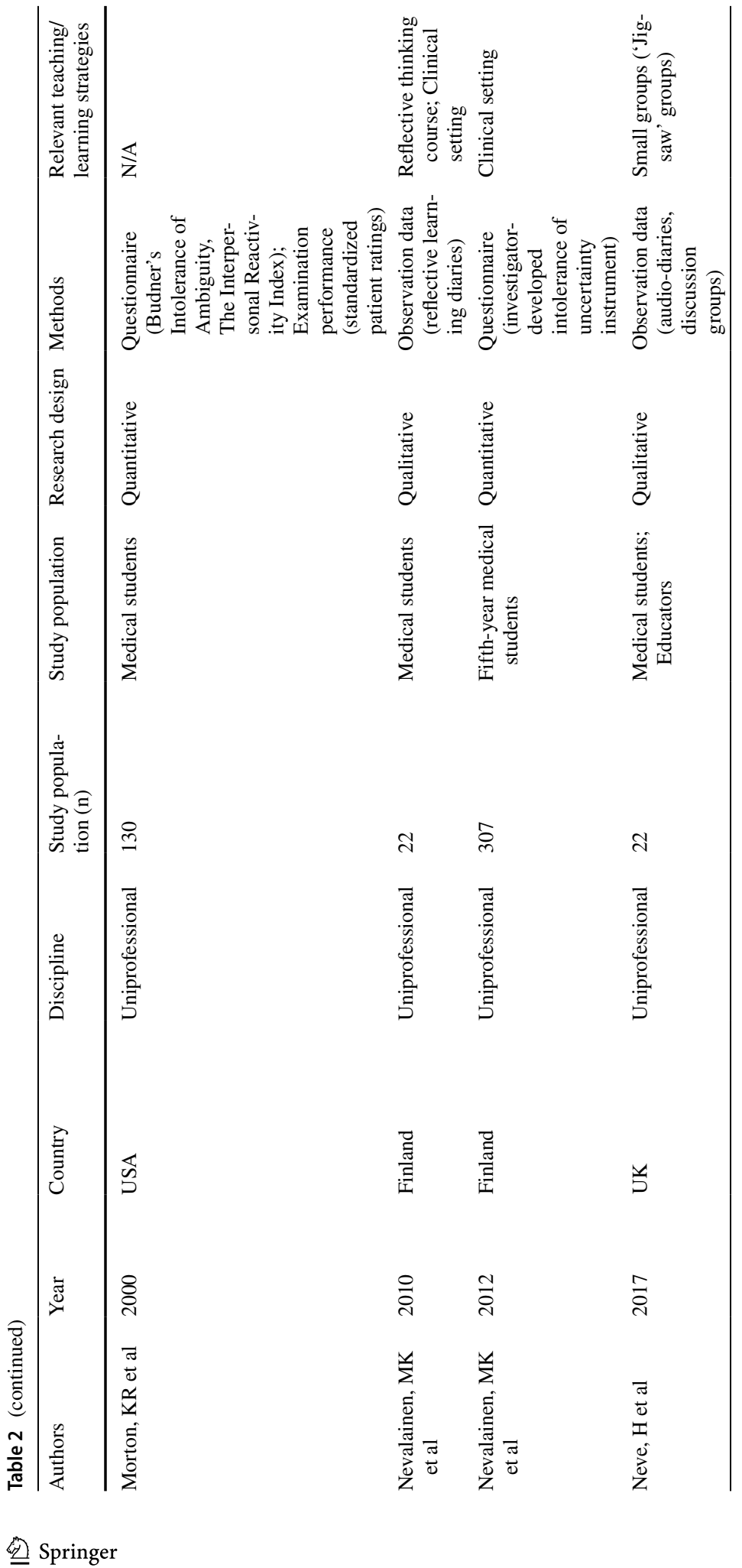




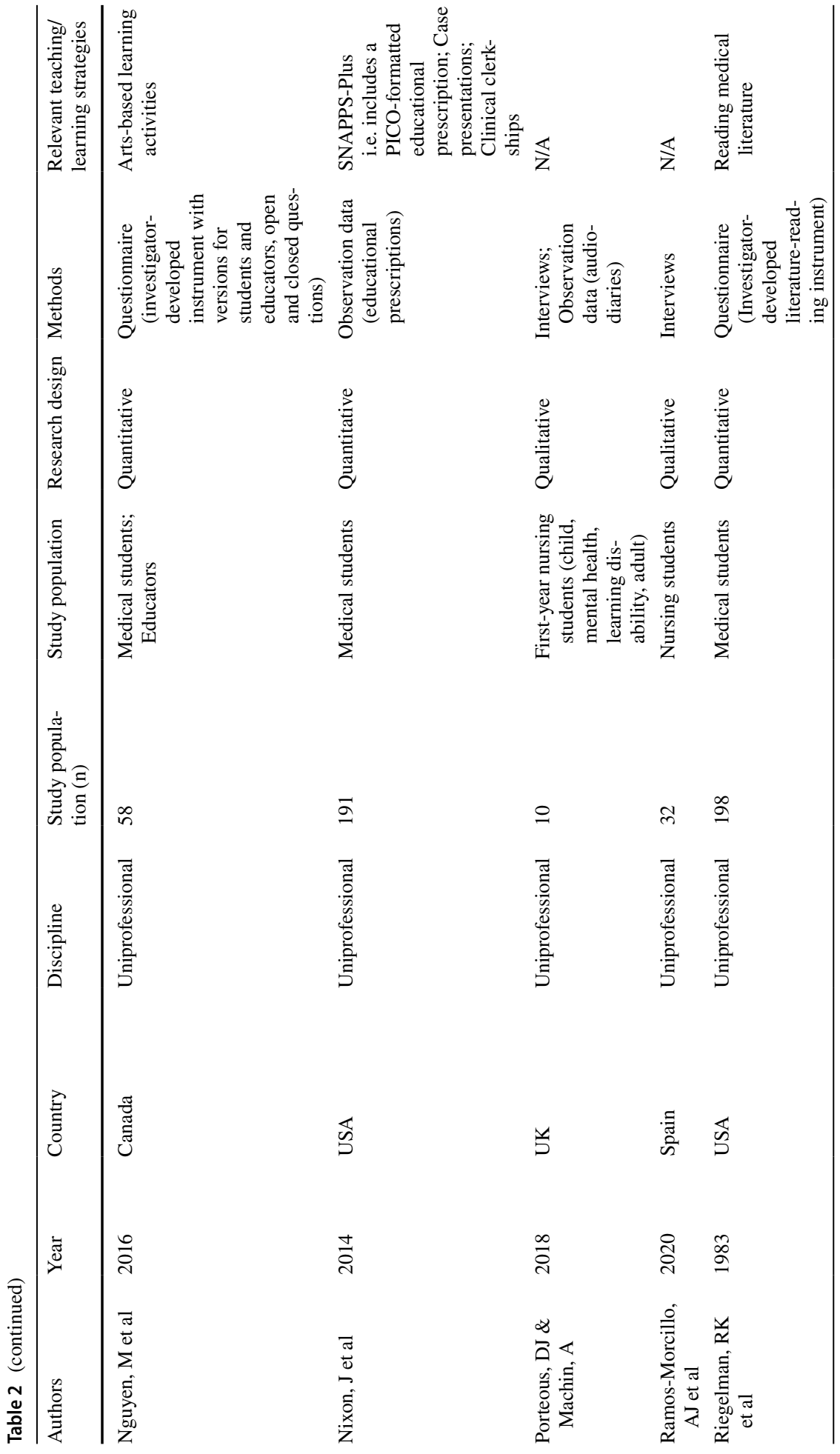




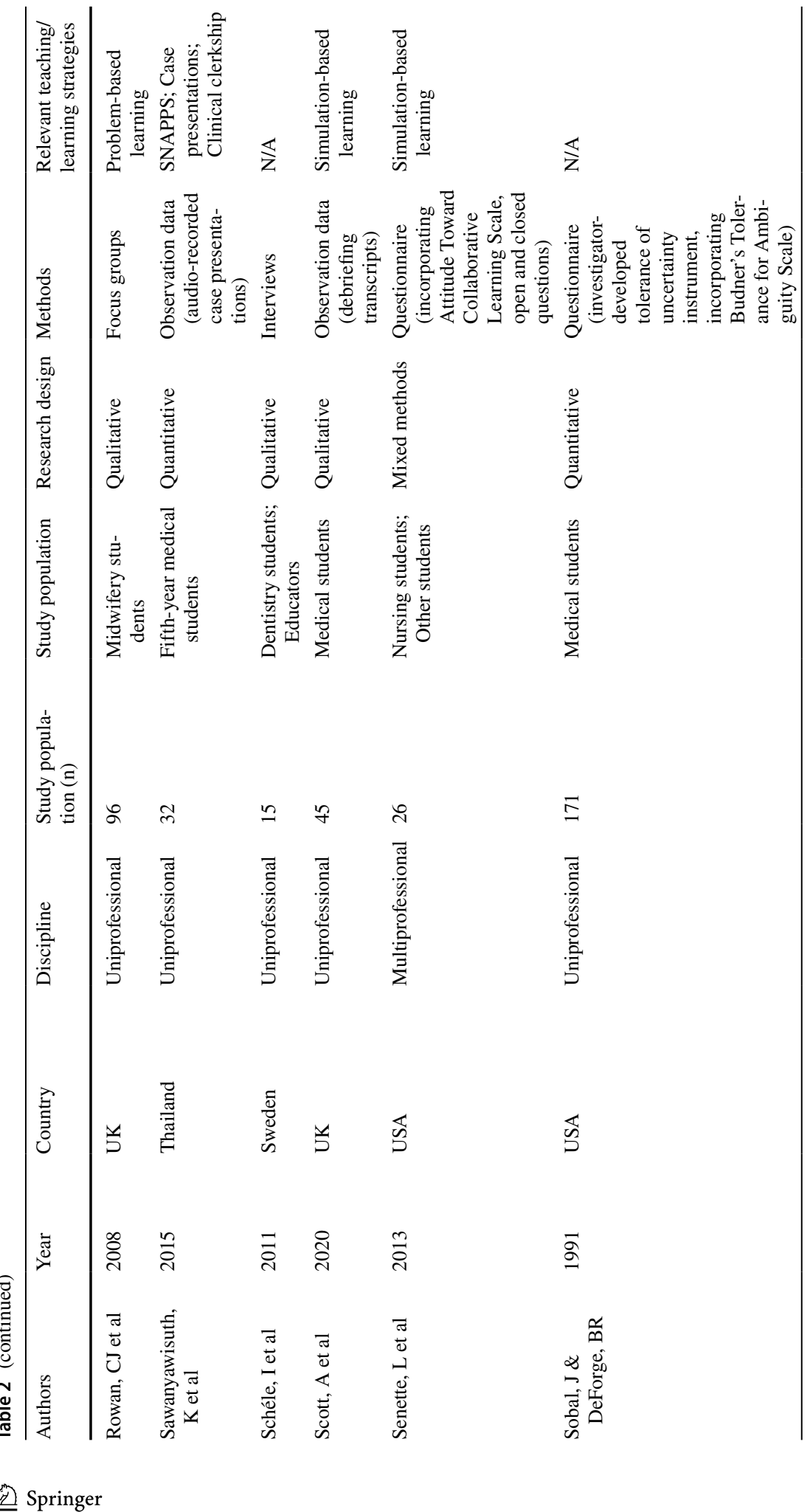




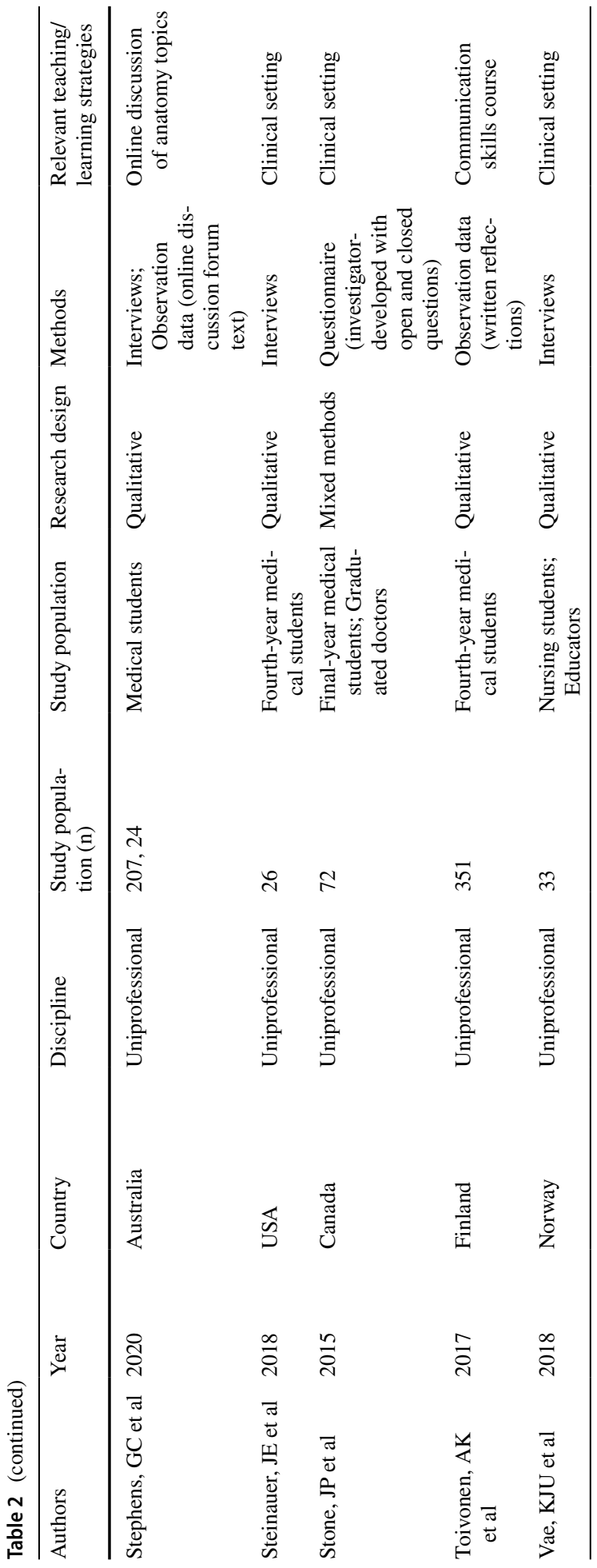




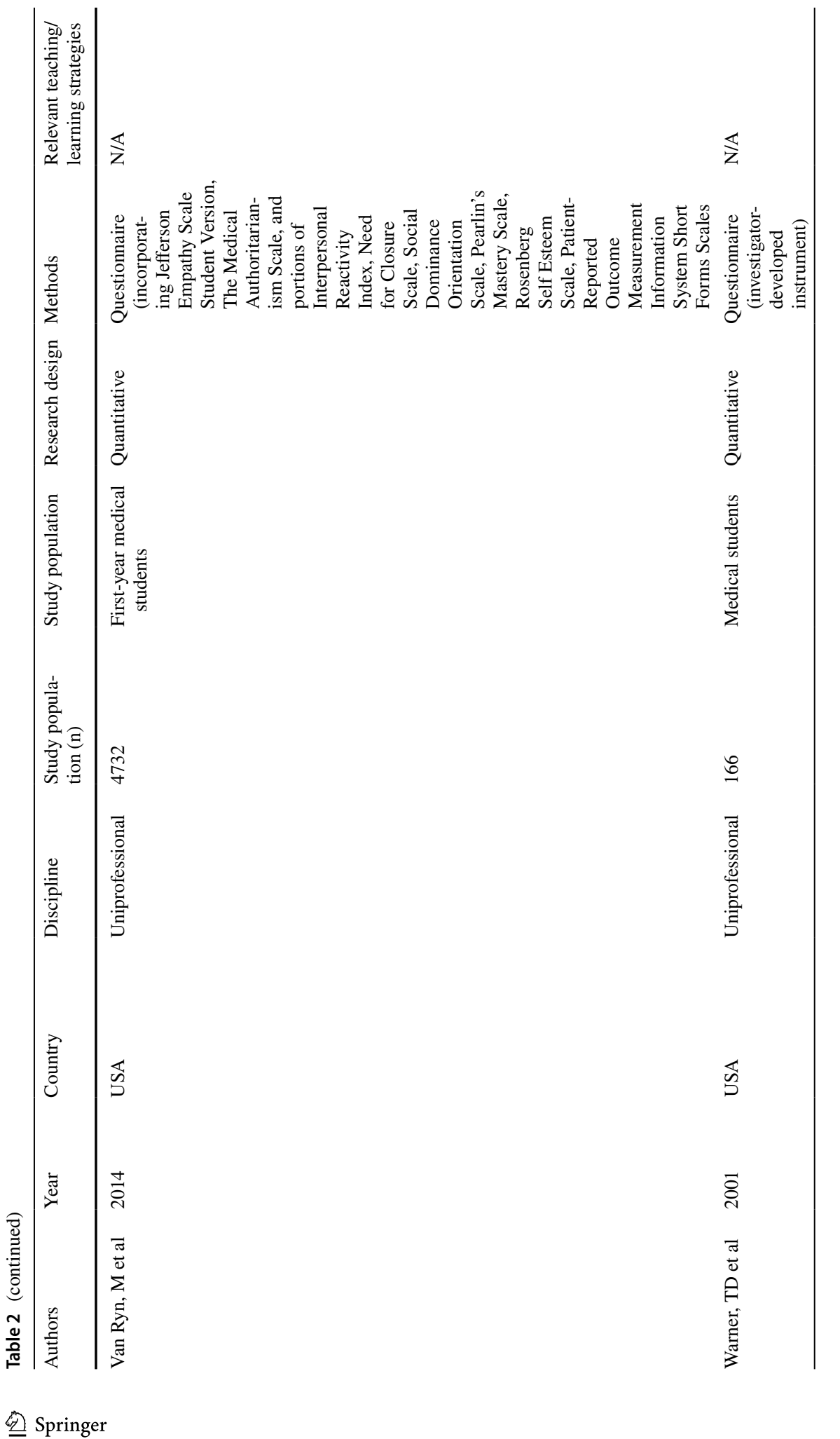




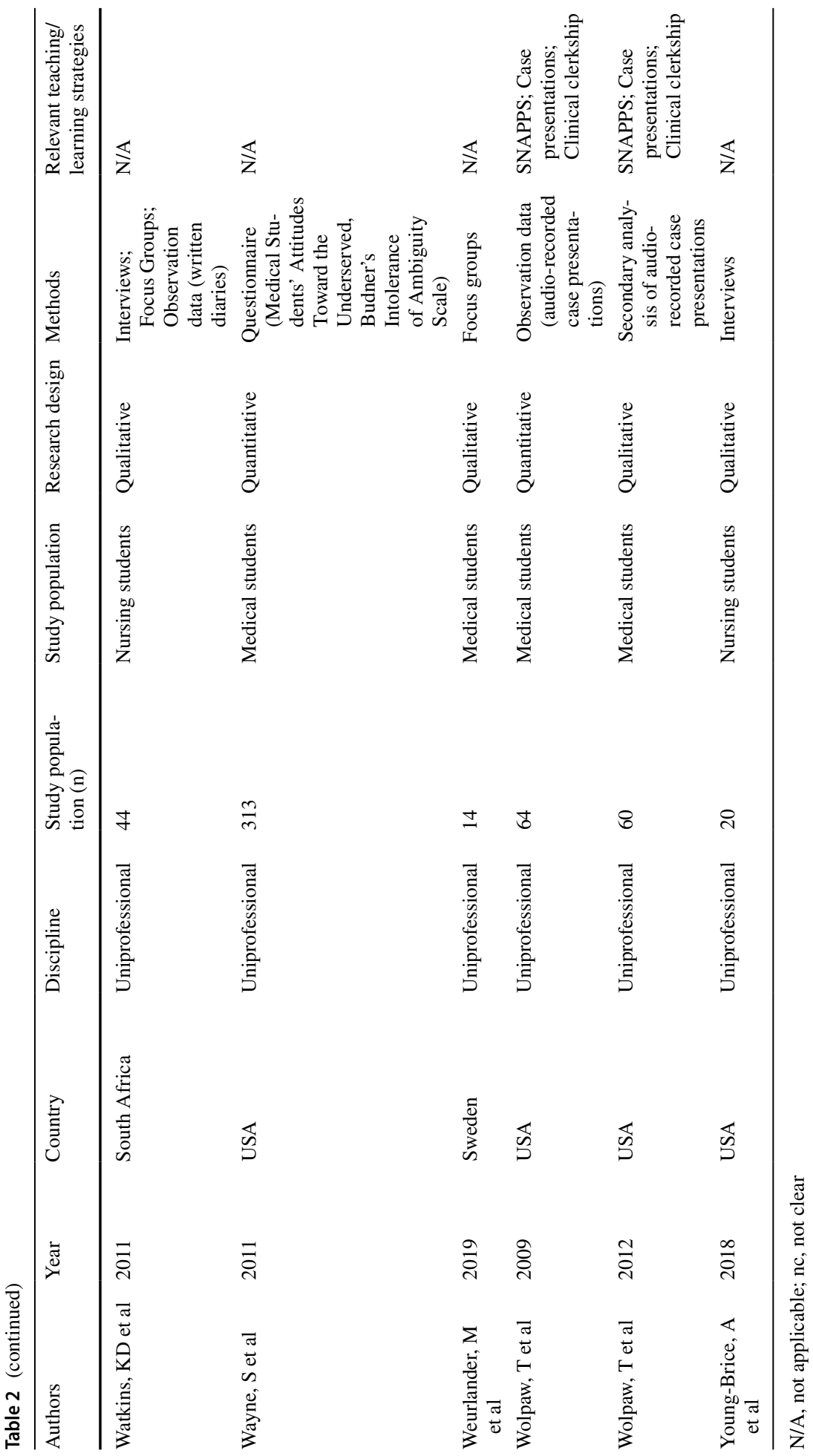




\section{Factors that influence learner experiences}

\section{Individual factors}

A large proportion of the literature examined individual learner differences with some evidence that gender, age, background, discipline, and stage of training could impact on how learners interact with uncertainty (Hancock et al. 2017; Bingyou 1991; Geller et al. 1990; Landeen et al. 2013; Nevalainen et al. 2010; DeForge and Sobal 1989; Eley et al. 2017; Young-Brice et al. 2018; Lodewyk et al. 2020; Jowsey et al. 2020). However, the heterogeneity of study designs made it difficult to draw general conclusions. For example, whilst some studies suggested that male students managed uncertainty better than female (Nevalainen et al. 2010), others suggested that females fared better (DeForge and Sobal 1989; Merrill et al. 1994; Geller et al. 1990); a further three papers found no gender differences (Sobal and Deforge 1991; Evans et al. 2012; Klugman et al. 2011). Several researchers commented on the multi-dimensional nature of uncertainty, and how different assessment instruments can lead to different outcomes (DeForge and Sobal 1989; Merrill et al. 1994; Hammond et al. 2017; P. K. J. Han et al. 2015).

\section{System factors}

Other studies identified a range of non-individual, or system, factors which influenced learners' experiences of uncertainty. Studies identified both local (i.e., specific clinic setting, organisational culture) (Senette et al. 2013; Ion et al. 2015; Markey et al. 2018, 2019; Weurlander et al. 2019), and wider (i.e., professional socialisation, socio-cultural issues) (Curtis 2014; McCarthy et al. 2018; Finnerty and Pope 2005; Sawanyawisuth et al. 2015; Al-Kloub et al. 2014; Frambach et al. 2012; Weurlander et al. 2019) contextual factors that impacted on how learners experience uncertainty. Several papers described a health professions' culture which, paradoxically, places value on certainty over uncertainty (Lingard et al. 2003a, 2003b; Riegelman et al. 1983).

\section{Educational outcomes}

\section{Negative narrative}

Overall, the narrative around learners' experience of uncertainty tended to be articulated in negative terms. Researchers described these experiences using words such as "discomfort", "stress", "anxiety", and "vulnerability" (Handwerker 2018; Krupat et al. 2011; Leh 2011; Porteous and Machin 2018; McCarthy et al. 2018; Markey et al. 2018; Toivonen et al. 2017; Dodgson et al. 2018; Ganesh and Ganesh 2010; Helmich et al. 2018; Llapa Rodrigues et al. 2016; Nevalainen et al. 2012; Watkins et al. 2011; Steinauer et al. 2018; Stone et al. 2015; Weurlander et al. 2019; Mol et al. 2019; Groot et al. 2020; Koufidis et al. 2020). This was particularly evident for studies which described nursing students' experiences in the clinical setting (Handwerker 2018; Porteous and Machin 2018; Llapa Rodrigues et al. 2016; Mc Carthy et al. 2018; Hazel et al. 2013; Leh 2011; Markey et al. 2018; Watkins et al. 2011; Leh 2011; Dodgson et al. 2018). 


\section{Learner approaches to uncertainty}

Several papers indicated that an ability to manage uncertainty represented an important component of learners' professional identity (Kristiansson et al. 2014; Mangione et al. 2018; Nevalainen et al. 2012; Neve et al. 2017). Learners themselves displayed a wide range of approaches to uncertainty (Nevalainen et al. 2012; Porteous and Machin 2018; Kristiansson et al. 2014; Markey et al. 2018, 2019; Helmich et al. 2018; Kashbour et al. 2019; Stephens et al. 2020). Strategies described in the literature included: learners letting go of perfectionism, adapting ideals to fit reality, being honest when lacking knowledge, asking for help, and understanding what it means to be "good enough"(Curtis 2014; Kristiansson et al. 2014; Schéle et al. 2011; Ganesh and Ganesh 2010; Nevalainen et al. 2012).

Learners tended to avoid or deny uncertainty, especially in assessment situations. Whilst some learners attempted to "self-preserve", by avoiding expressions of uncertainty (Lingard et al. 2003a, b) and avoiding asking questions (Markey et al. 2018; Huijer et al. 2000), others appeared to place blame onto patients (Steinauer et al. 2018). This position was countered by one qualitative study, which found scant evidence of a denial of uncertainty in their medical student cohort (Kristiansson et al. 2014). Several papers highlighted the importance of socio-cultural background, e.g., country of origin, on learners' likelihood to respond openly to uncertainty (Al-Kloub et al. 2014; Frambach et al. 2012; Sawanyawisuth et al. 2015).

Many researchers described a maturation process, i.e., that learners' responses to uncertainty evolve as they accumulate experience and academic maturity (Kristiansson et al. 2014; Landeen et al. 2013; Nevalainen et al. 2010, 2012; Sobal and Deforge 1991; Merrill et al. 1994; Lingard et al. 2003b; Neve et al. 2017; Han et al. 2015; Riegelman et al. 1983; Balentine et al. 2010; Stephens et al. 2020). Only one study indicated that uncertainty tolerance did not change as learners progressed through their training, a finding which may relate to the study's cross-sectional design (Geller et al. 1990).

\section{Impact on learning}

Several papers discussed the links between students' capacity to manage uncertainty and their academic performance (Ironside et al. 2009; Morton et al. 2000; Groot et al. 2020), career preferences (Eley et al. 2017; Geller et al. 1990; Merrill et al. 1994; Nevalainen et al. 2010), ability to empathise (Markey et al. 2018; Mangione et al. 2018; Morton et al. 2000; van Ryn et al. 2014), and attitudes towards patients (Steinauer et al. 2018; Geller et al. 1990; Wayne et al. 2011; Merrill et al. 1994; Lingard et al. 2003b) with mixed and occasionally conflicting findings. Several papers proposed that uncertainty presents a barrier to learning, i.e., causing students to become less self-directed, proactive, and effortful in their learning (Al-Kloub et al. 2014; Frambach et al. 2012; Finnerty and Pope 2005; Duvivier et al. 2014). Other researchers commented that uncertainty under certain circumstances could be "productive", i.e., where appropriate supports are in place, this can act as a catalyst for learning (Friary et al. 2018; McCarthy et al. 2018; Kashbour et al. 2019).

\section{Teaching and learning approaches}

Several studies focused on existing approaches to teaching and learning around uncertainty from the perspectives of content ("what") and process ("how"). With regards to 
the former, learners met uncertainty when engaging with topics such as professionalism, communication, ethics, clinical reasoning, evidence-based medicine, and interprofessional learning (Han et al. 2014, 2015; Hazel et al. 2013; Chan and Nyback 2015; Lemmon et al. 2018; Johnsen 2016; Ironside 2003; Jowsey et al. 2020). With regards to the latter, a number of formal teaching strategies which intended to help learners to work with uncertainty, were described. These studies largely fell into two groups: arts-based teaching which addressed issues of uncertainty and ambiguity (Klugman et al. 2011; Nguyen et al. 2016; Bentwich and Gilbey 2017; He et al. 2019), and clinical teaching which used SNAPPS, a clinical reasoning scaffold with a specific focus on identifying uncertainties (Nixon et al. 2014; Sawanyawisuth et al. 2015; Wolpaw et al. 2009, 2012; Fagundes et al. 2020). Other studies suggested that learners could develop ways to manage uncertainty through use of the Learning-by-Concordance approach (Fernandez et al. 2016), simulation (Scott et al. 2020) and a novel equine-facilitated workshop which introduced horses to medical students as "experiential surrogates for ambiguity" (Liou et al. 2019).

Learners also had opportunities to develop their capacity to manage uncertainty in other, more indirect ways, e.g., through problem-based learning (Maudsley et al. 2008; Rowan et al. 2008; Landeen et al. 2013; Koh et al. 2008) and simulation (Senette et al. 2013; Gormley and Fenwick 2016; Bintley et al. 2019; Gärtner et al. 2020; Groot et al. 2020; Jowsey et al. 2020). With regards to the former, researchers recommended that sessions should be actively tutored, and cases not overtly scripted, to support learning around uncertainty (Landeen et al. 2013; Biley and Smith 1999; Maudsley et al. 2008). Teaching in the clinical setting was also important, with an emphasis on building supportive educator-learner relationships (Lingard et al. 2003b; Finnerty and Pope 2005; Porteous and Machin 2018; Curtis et al. 2012).

Other educational strategies that emerged included team-based learning (Hazel et al. 2013), small group learning (Gibson et al. 2014; Chan and Nyback 2015), tactical games (Drummond et al. 2016), virtual patients (Hayward et al. 2016), online discussion of anatomy topics (Stephens et al. 2020), and non-specified humanistic activities (Mangione et al. 2018; Gaufberg et al. 2018). Reflective practice was also mentioned within the literature and researchers described a variety of techniques which could be usefully applied, including: discussions with mentors (Finnerty and Pope 2005; Kashbour et al. 2019), small group exercises (Neve et al. 2017; Ali et al. 2017), written reflection (Kristiansson et al. 2014; Ganesh and Ganesh 2010; Brondani and Donnelly 2020), and combinations of these (Nguyen et al. 2016; Chan and Nyback 2015; Gowda et al. 2018; Nevalainen et al. 2010; Toivonen et al. 2017; Kashbour et al. 2019).

Specific teaching approaches to support learning around uncertainty were mentioned within the studies. These included: helping learners to reach a sense of "good enough" (Kristiansson et al. 2014); encouraging learners to keep questioning what they think they know (Ali et al. 2017); directly acknowledging that ambiguity and uncertainty exist within health professions' work (Wayne et al. 2011; Weurlander et al. 2019); helping learners to understand that success has different meanings; teaching thinking in ways that preserve uncertainty and fallibility (Ironside 2003); managing expectations around controlling uncertainty (Helmich et al. 2018); leveraging learners' experiences of uncertainty in non-academic settings such as sports participation (Lodewyk et al. 2020), and providing extra support to ethnic minority students (Young-Brice et al. 2018). Table 3 shows a summary of our major findings. 


\section{Discussion}

In seeking to explore how undergraduate health professions' students learn to engage with uncertainty in their professional practice, this review highlights that the experience of uncertainty is ubiquitous within their education. It is clear that a wide variety of learners, from different professions and countries, engage with uncertainty at all stages of their training.

The review sheds light on the nuances of uncertainty for health professions' learners. Different types exist; from the uncertainty related to interactions with the healthcare and educational processes, to the uncertainty students experience in relation to their own selves. These types of uncertainty arise for learners in many varied teaching and learning settings (although uncertainty related to lecture-based teaching was conspicuous in its absence). Problem-based learning seems to provide an important crucible for engaging with uncertainty, as does workplace-based learning. Our review also reinforces the idea that transitions, e.g., entering clinical rotations, provoke experiences of uncertainty for health professions' learners (Teunissen and Westerman, 2011; Ingvarsson et al. 2019).

In keeping with the wider literature, this review highlights the various ways in which learners navigate uncertainty, and that both individual and context-related factors influence this process. It seems that learners also build a capacity to manage uncertainty as they progress through their training. Several studies refer to this phenomenon as a "maturation process", and it's unclear to what extent this unfolds due to students' accumulation of learning and experience, or to socialisation within their chosen profession. Our findings lack detail around what, specifically, this maturation looks like. Existing longitudinal studies tend to track learners' engagement with uncertainty through the lens of a psychological construct, i.e. tolerance of uncertainty (Hillen et al. 2017). However, cross-sectional qualitative studies suggest that the learners mobilise a wide range of knowledge, skills and attitudes in relation to uncertainty, a level of granular detail which may not be captured fully by existing research designs.

Whilst our review suggests that students meet with uncertainty many times during their training, there were few examples of direct teaching, i.e., through arts-based approaches (Klugman et al. 2011; Nguyen et al. 2016; Bentwich and Gilbey 2017; He et al. 2019) or clinical cases (Nixon et al. 2014; Sawanyawisuth et al. 2015; Wolpaw et al. 2009, 2012; Fernandez et al. 2016; Fagundes et al. 2020). When compared to other non-technical domains such as communication and team skills, this apparent scarcity is surprising (Buljac-Samardzic et al. 2010; Berkhof et al. 2011). This finding might be explained by how uncertainty and its management is conceptualised. Until recently, tolerance of uncertainty has largely been framed as a stable personality trait, although it is now considered at least partly amenable to training (Strout et al. 2018). The idea that the capacity to manage uncertainty is personality-driven, and is mostly taught indirectly rather than directly within health professions' education, recalls the early days of the communication skills movement. Thirty years ago we asked ourselves "can communication skills be taught?"(Maguire 1990); could uncertainty management occupy a similar trajectory?

There may also be a reluctance to provide training around uncertainty due to its perception as a difficult, uncomfortable topic for healthcare professionals. Our review highlights a negative narrative around managing uncertainty, with learners' frequently discussing it in terms of stress or strain. These descriptions link back to the wider literature which connects uncertainty with feelings of discomfort and anxiety (Carleton 2016; Shihata et al. 2016; Mishel 1984; Penrod 2001; Ilgen et al. 2018). In our review, 
this negativity was most apparent within cohorts of clinical nursing students. It is not clear whether there are particular characteristics to this context which are specifically negative, or if, perhaps, nursing students' are more inclined to express and discuss the emotional aspects of their practice?

What this review does outline is that students' experiences of uncertainty have several effects. In some cases, uncertainty acts as a barrier to learning (Al-Kloub et al. 2014; Frambach et al. 2012; Duvivier et al. 2014; Finnerty and Pope 2005; Scott et al. 2020). In others, it elicits behaviour change e.g., learners attempt to "self-preserve", by avoiding expressions of uncertainty (Lingard et al. 2003a, 2003b) or even placing blame onto patients (Steinauer et al. 2018). This supports the idea that health professions' learners feel pressure to preserve the semblance of competence in front of their teachers, engaging in impression management (Lo and Regehr 2017; McGaghie 2018; Patel et al. 2018).

The included studies say less on the benefits of engaging with uncertainty. One study (Friary et al. 2018) proposes that "some uncertainty or stress is needed to shift learning to a new level." This is supported in the educational literature, where there is a growing recognition that experiences of uncertainty are important catalysts for deeper learning (Overoye and Storm 2015; Lodge et al. 2018). However, the authors highlight that uncertainty is only "productive" under certain circumstance i.e., when it does not undermine trust and confidence. It implies then that some experiences of uncertainty may be more helpful than others to students. This idea has been discussed previously with the idea that "good uncertainty... provides students opportunities to engage with the unknowns of a challenge in an otherwise supportive, well-structured environment", whilst "bad" uncertainty can result in chaos (Beghetto 2017). In a health professions' context we might hypothesise that a student who interacts with a patient from a different socio-cultural background, experiences a "productive" uncertainty, whilst one who can't locate their classroom experiences one that is "unproductive". There appears to be little objective data, and a gap in the literature, in relation to how these experiences are perceived and managed by students, and what outcomes result.

Despite the further issues that this review provokes around how learners engage with uncertainty, we do know that there are many opportunities for health professions' educators to support them on this journey. Topics that commonly appear on health professions' curricula, e.g., professionalism, communication, ethics, clinical reasoning, can provide a "home" for learning around uncertainty. Similarly, teaching settings such as problem-based learning contexts, and the clinical workplace lend themselves to experiential learning around this domain. Finally, educators can help their learners to manage and make sense of uncertain situations through supportive mentoring and role modelling, and through involving them in well-structured reflective exercises (Uygur et al. 2019).

\section{Future research}

With regards to future research, an increased focus on longitudinal studies which employ qualitative or mixed method approaches could provide more detailed information on how students build their capacity to manage uncertainty during their training. Further work is also required to explore how learners' experiences with specific types of uncertainty impact on learning processes, i.e., can we recognise and foster more "productive" experiences of uncertainty for students? Finally, expanding the scoping review approach to cover postgraduate training and cross-cultural studies, would improve our understanding of this issue. 


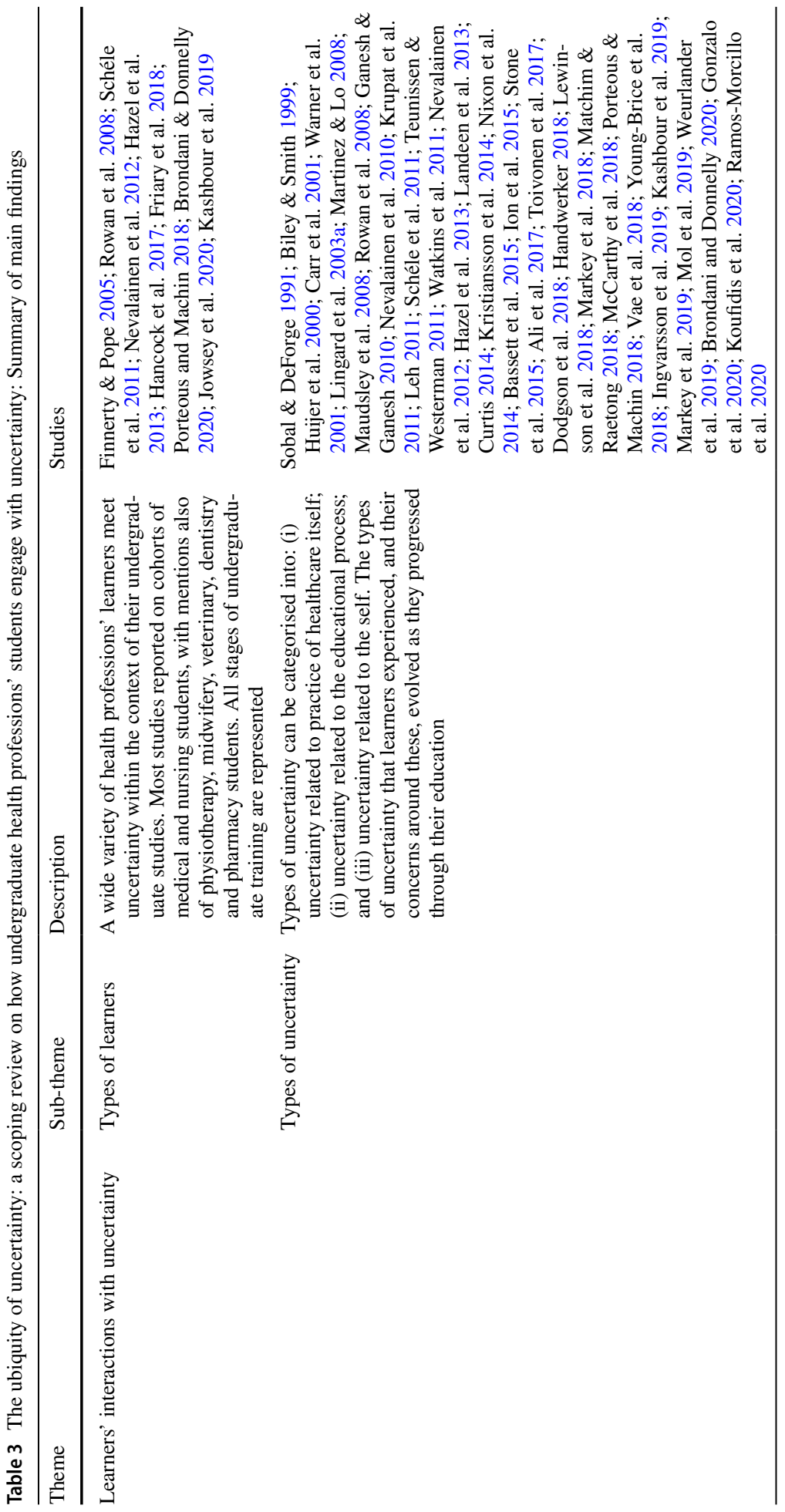




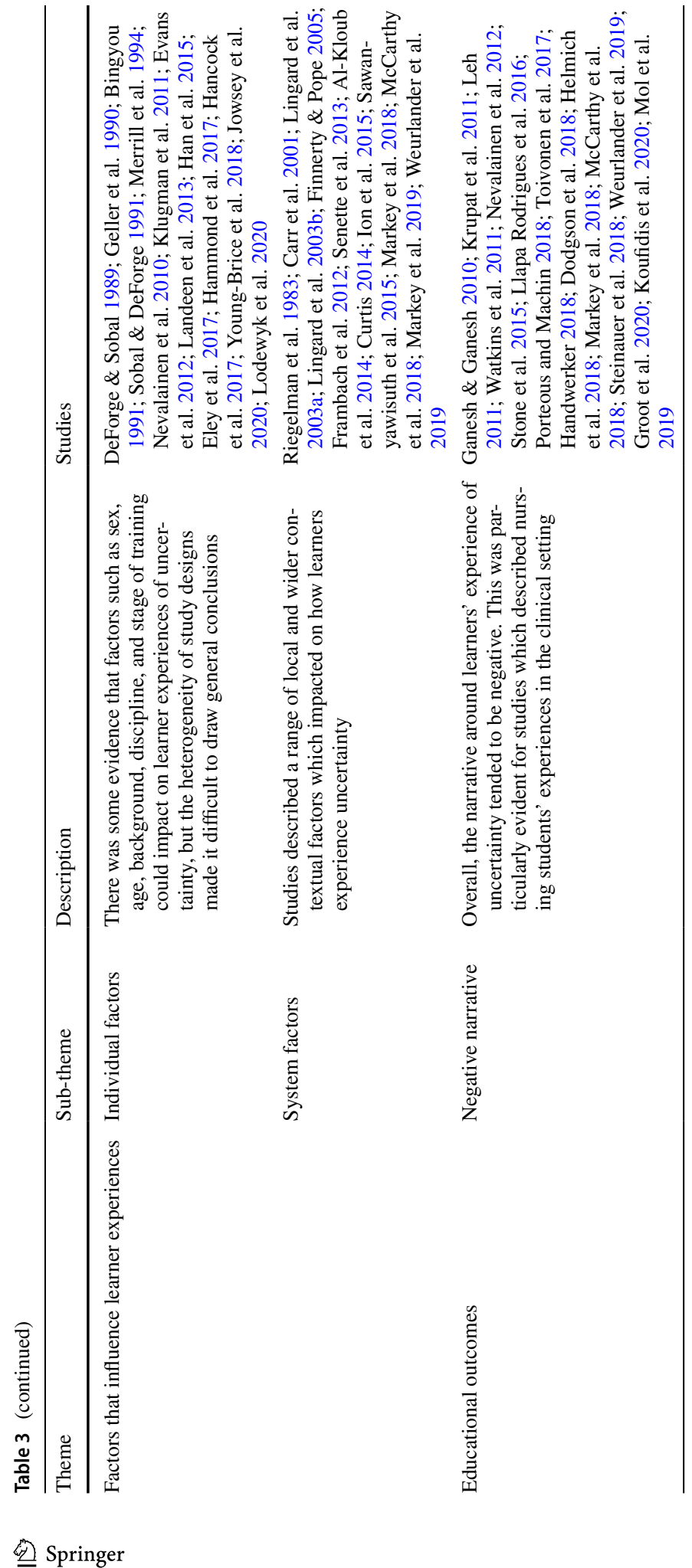




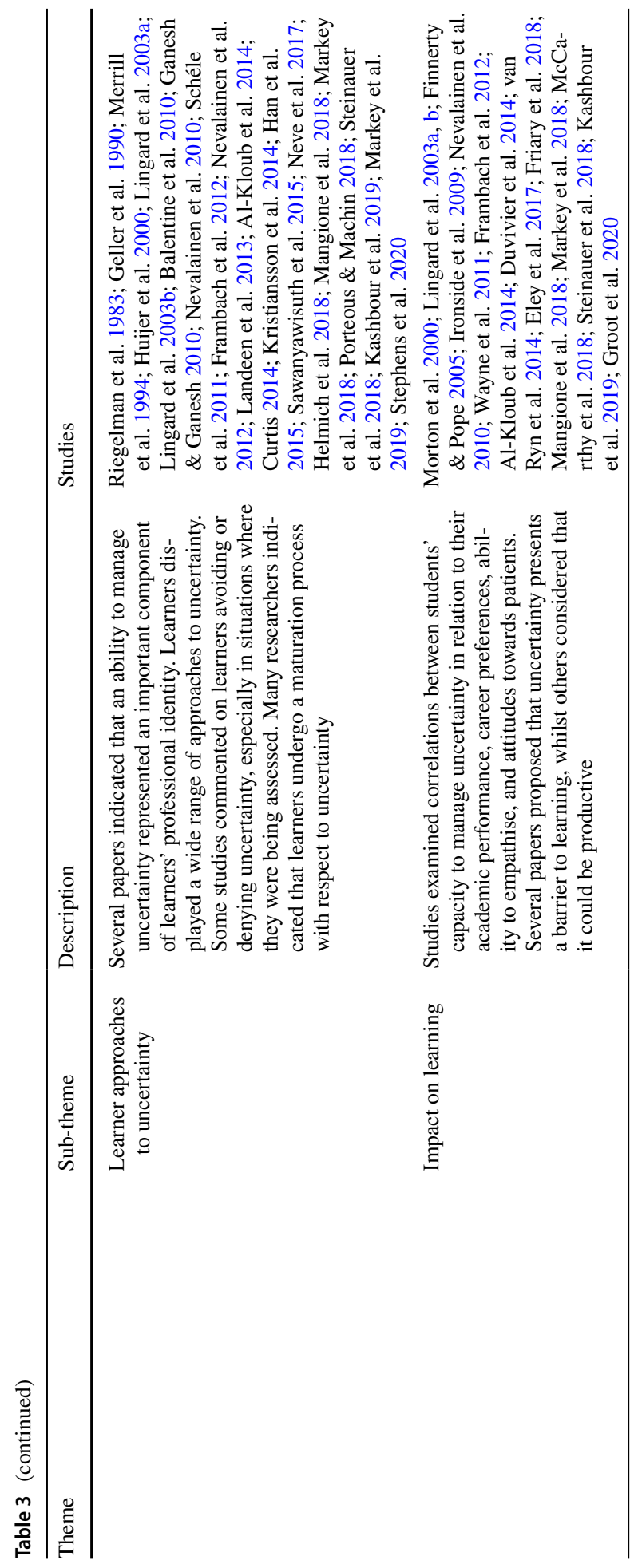




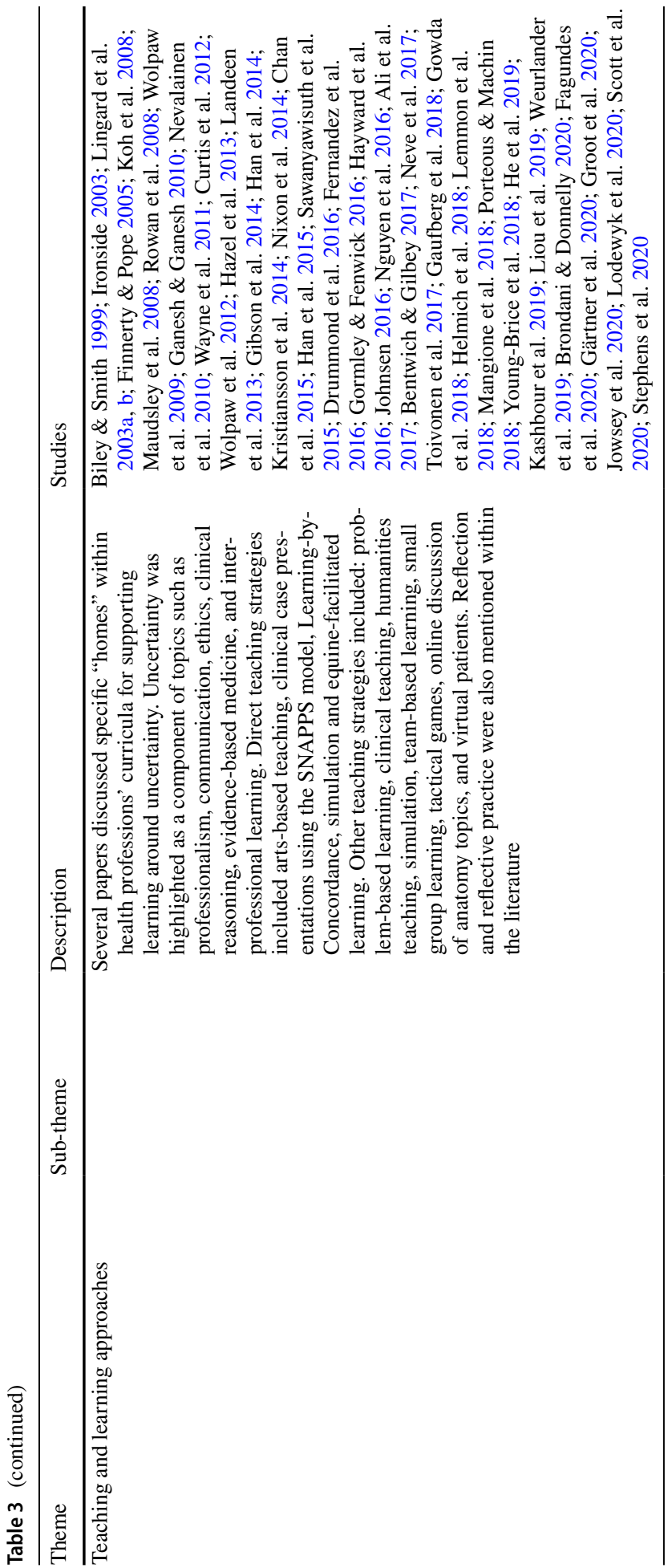




\section{Strengths and limitations}

We used a broad search strategy in order to maximise inclusivity and generate an overview of uncertainty in the literature. Thus we kept the initial search open to all levels of health professions' training, an approach which yielded a high volume of papers. To limit the papers to a feasible data set, we chose to focus only on "uncertainty" and "ambiguity" (although we had tested other synonyms). Similarly, we restricted our searches to papers published during or after 1950, and to those published in the English language. Given the potential breadth of the field, future reviews may consider using variations of the search strategy we have documented, and might include utilising forward citation methods to improve the sensitivity and specificity of the literature search results.

\section{Conclusions}

Training for uncertainty has been described as medical education's "most elusive ideal" 28 . This scoping review allows us to track down this concern, providing an overview of how health professions' students learn to engage with uncertainty during their undergraduate training. We have found that uncertainty is a ubiquitous concern in health professions' education, with students experiencing different forms of uncertainty at many stages of their training. These experiences are influenced by both individual and system-related factors.

Whilst formal teaching to support learning around uncertainty is infrequent, specific strategies do exist, i.e., arts-based teaching, and clinical case presentations. Other types of teaching provide ways for students to meet with uncertainty indirectly, including problembased learning, clinical teaching, humanities teaching, simulation, team-based learning, small group learning, tactical games, and virtual patients. Reflection and reflective practice are also mentioned as strategies to address learner experiences of uncertainty within the literature.

\section{Appendix 1}

Preferred reporting items for systematic reviews and meta-analyses extension for scoping reviews (PRISMA-ScR) checklist.

\begin{tabular}{|c|c|c|c|}
\hline Section & Item & PRISMA-ScR checklist Item & Reported on page \# \\
\hline \multicolumn{4}{|l|}{ Title } \\
\hline Title & 1 & Identify the report as a scoping review & 1 \\
\hline \multicolumn{4}{|l|}{ Abstract } \\
\hline Structured summary & 2 & $\begin{array}{l}\text { Provide a structured summary that } \\
\text { includes (as applicable): back- } \\
\text { ground, objectives, eligibility cri- } \\
\text { teria, sources of evidence, charting } \\
\text { methods, results, and conclusions } \\
\text { that relate to the review questions } \\
\text { and objectives }\end{array}$ & 1 \\
\hline Introduction & & & \\
\hline
\end{tabular}




\begin{tabular}{|c|c|c|c|}
\hline Section & Item & PRISMA-ScR checklist Item & Reported on page \# \\
\hline Rationale & 3 & $\begin{array}{l}\text { Describe the rationale for the review } \\
\text { in the context of what is already } \\
\text { known. Explain why the review } \\
\text { questions/objectives lend themselves } \\
\text { to a scoping review approach }\end{array}$ & 3 \\
\hline Objectives & 4 & $\begin{array}{l}\text { Provide an explicit statement of the } \\
\text { questions and objectives being } \\
\text { addressed with reference to their key } \\
\text { elements (e.g., population or par- } \\
\text { ticipants, concepts, and context) or } \\
\text { other relevant key elements used to } \\
\text { conceptualize the review questions } \\
\text { and/or objectives }\end{array}$ & 5 \\
\hline
\end{tabular}

\section{Methods}

Protocol and registration

Eligibility criteria

Information sources*

Search

Selection of sources of evidence $†$

Data charting process $\ddagger$

Data items
5 Indicate whether a review protocol exists; state if and where it can be accessed (e.g., a Web address); and if available, provide registration information, including the registration number

6 Specify characteristics of the sources of evidence used as eligibility criteria (e.g., years considered, language, and publication status), and provide a rationale

Describe all information sources in the search (e.g., databases with dates of coverage and contact with authors to identify additional sources), as well as the date the most recent search was executed

8 Present the full electronic search strategy for at least 1 database, including any limits used, such that it could be repeated

9 State the process for selecting sources of evidence (i.e., screening and eligibility) included in the scoping review

10 Describe the methods of charting data from the included sources of evidence (e.g., calibrated forms or forms that have been tested by the team before their use, and whether data charting was done independently or in duplicate) and any processes for obtaining and confirming data from investigators

11 List and define all variables for which 7 data were sought and any assumptions and simplifications made

Appendix 2 


\begin{tabular}{llll}
\hline Section & Item & PRISMA-ScR checklist Item & Reported on page \# \\
\hline $\begin{array}{l}\text { Critical appraisal of individual sources } \\
\text { of evidence§ }\end{array} 12$ & $\begin{array}{l}\text { If done, provide a rationale for } \\
\text { conducting a critical appraisal } \\
\text { of included sources of evidence; } \\
\text { describe the methods used and how } \\
\text { this information was used in any } \\
\text { data synthesis (if appropriate) }\end{array}$ \\
Synthesis of results & $13 \quad \begin{array}{l}\text { Describe the methods of handling } \\
\text { and summarizing the data that were } \\
\text { charted }\end{array}$ & 7,8 \\
Results & &
\end{tabular}

Selection of sources of evidence

Characteristics of sources of evidence

Critical appraisal within sources of evidence Results of individual sources of
evidence

Synthesis of results

\section{Discussion}

Summary of evidence

Limitations

Conclusions

Funding

Funding
14 Give numbers of sources of evidence screened, assessed for eligibility, and included in the review, with reasons for exclusions at each stage, ideally using a flow diagram

15 For each source of evidence, present characteristics for which data were charted and provide the citations

16 If done, present data on critical appraisal of included sources of evidence (see item 12)

17 For each included source of evidence, Table 2 present the relevant data that were charted that relate to the review questions and objectives

18 Summarize and/or present the charting Table 3 results as they relate to the review questions and objectives

19 Summarize the main results (including 15-19 an overview of concepts, themes, and types of evidence available), link to the review questions and objectives, and consider the relevance to key groups

20 Discuss the limitations of the scoping review process

21 Provide a general interpretation of the results with respect to the review questions and objectives, as well as potential implications and/or next steps

Table 2

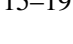


* where sources of evidence (see second footnote) are compiled from, such as bibliographic databases, social media platforms, and Web sites.

$\dagger$ A more inclusive/heterogeneous term used to account for the different types of evidence or data sources (e.g., quantitative and/or qualitative research, expert opinion, and policy documents) that may be eligible in a scoping review as opposed to only studies. This is not to be confused with information sources (see first footnote).

$\ddagger$ The frameworks by Arksey and O’Malley (6) and Levac and colleagues (7) and the JBI guidance $(4,5)$ refer to the process of data extraction in a scoping review as data charting.

$\S$ The process of systematically examining research evidence to assess its validity, results, and relevance before using it to inform a decision. This term is used for items 12 and 19 instead of "risk of bias" (which is more applicable to systematic reviews of interventions) to include and acknowledge the various sources of evidence that may be used in a scoping review (e.g., quantitative and/or qualitative research, expert opinion, and policy document).

\section{Appendix 2}

The ubiquity of uncertainty: a scoping review on how undergraduate health professions' students engage with uncertainty: search strategy used for MEDLINE.

\section{PubMed}

1
(education[Title/Abstract]) OR educational[Title/ Abstract] OR learning[Title/Abstract] OR "Learning"[Mesh] OR "Social Learning"[Mesh] OR "Education, Professional"[Mesh] OR "Education, Pharmacy, Graduate"[Mesh] OR "Education, Pharmacy"[Mesh] OR "Education, Nursing, Graduate"[Mesh] OR "Education, Nursing, Diploma Programs"[Mesh] OR "Education, Nursing, Continuing"[Mesh] OR "Education, Nursing, Baccalaureate"[Mesh] OR "Education, Nursing, Associate"[Mesh] OR "Education, Nursing"[Mesh] OR "Education, Medical, Undergraduate"[Mesh] OR "Education, Medical, Graduate"[Mesh] OR "Education, Medical, Continuing"[Mesh] OR "Education, Medical"[Mesh] OR "Education, Graduate"[Mesh] OR "Education, Dental, Graduate"[Mesh] OR "Education, Dental, Continuing"[Mesh] OR "Education, Dental"[Mesh] OR "Educational Measurement”[Mesh])

((student[Title/Abstract] or students[Title/Abstract]) AND (medical[Title/Abstract]] OR medicine[Title/ Abstract] OR nursing[Title/Abstract] OR midwifery[Title/Abstract] OR midwives[Title/ Abstract] OR pharmacy[Title/Abstract] OR pharmacist[Title/Abstract] OR physiotherapist[Title/ Abstract) OR physiotherapists[Title/Abstract] OR dentist[Title/Abstract] OR dentists[Title/Abstract] OR veterinary[Title/Abstract] OR dental[Title/Abstract] OR "Students, Premedical"[Mesh] OR "Students, Pharmacy"[Mesh] OR "Students, Nursing"[Mesh] OR "Students, Medical"[Mesh] OR "Students, Health Occupations"[Mesh] OR "Students, Dental"[Mesh]) (uncertainty[Title/Abstract] or ambiguity[Title/Abstract]) 1 AND 2 AND 3 


\section{Appendix 3}

The ubiquity of uncertainty: a scoping review on how undergraduate health professions' students engage with uncertainty: key health professions' journals that were hand-searched during this review.

Hand searched health professions' journals

Academic Emergency Medicine
Academic Medicine
Advances in Health Sciences Education
BMC Medical Education
Health Professions Education
International Journal of Medical Education
International Journal of Nursing Studies
Journal of Dental Education
Journal of Veterinary Medical Education
Medical Education
Medical Teacher
Midwifery
Möbius: A Journal for Continuing Educa-
tion Professionals in Health Sciences
The Clinical Teacher

Acknowledgements We would like to express our sincere gratitude to Drs Erica Smith, Muirne Spooner and Aisling Kerr for their generous peer support during the scoping review process.

Author contributions JM, JH and TP: conceptualised the study; JM, JH, TP and PM: contributed to the study design; JM and JH: led the data collection and analysis with support from TP; JM: produced the first draft of the paper; all four authors (JM, JH, TP and PM) contributed to and refined this draft. All four authors approved the final manuscript for submission.

Funding Internal funding from RCSI HPEC (Health Professions' Education Centre) was provided for this paper.

Open Access This article is licensed under a Creative Commons Attribution 4.0 International License, which permits use, sharing, adaptation, distribution and reproduction in any medium or format, as long as you give appropriate credit to the original author(s) and the source, provide a link to the Creative Commons licence, and indicate if changes were made. The images or other third party material in this article are included in the article's Creative Commons licence, unless indicated otherwise in a credit line to the material. If material is not included in the article's Creative Commons licence and your intended use is not permitted by statutory regulation or exceeds the permitted use, you will need to obtain permission directly from the copyright holder. To view a copy of this licence, visit http://creativecommons.org/licenses/by/4.0/.

\section{References}

Academy of Medical Royal Colleges (2009). Common competences framework for doctors. Retrieved from: https://www.aomrc.org.uk/wp-content/uploads/2018/03/CCFD-August-2009-1.pdf

Ali, M. A., Bishop, S., \& Martin, B. (2017). Learning to Work with Immigrant Families: An Experiment in Experiential Learning. Canadian Journal for the Scholarship of Teaching and Learning. https://doi. org/10.5206/cjsotl-rcacea.2017.3.4.

Al-Kloub, M. I., Salameh, T. N., \& Froelicher, E. S. (2014). Nursing students evaluation of problem based learning and the impact of culture on the learning process and outcomes: A pilot project. Nurse Education in Practice, 14(2), 142-147. https://doi.org/10.1016/j.nepr.2013.06.013. 
Arksey, H., \& O’Malley, L. (2005). Scoping studies: Towards a methodological framework. International Journal of Social Research Methodology, 8(1), 19-32.

Atkinson, P. (1984). Training for certainty. Social science and Medicine, 19(9), 949-956.

Balentine, C. J., Ayanbule, F., Haidet, P., Rogers, J., Thompson, B., et al. (2010). The patient-Physician relationship in surgical students. The American Journal of Surgery, 200(5), 624-627.

Bassett, A. M., Baker, C., \& Cross, S. (2015). Religion, assessment and the problem of "normative uncertainty" for mental health student nurses: A critical incident-informed qualitative interview study. Journal of Psychiatric and Mental Health Nursing, 22(8), 606-615. https://doi.org/10.1111/ jpm. 12225 .

Beghetto, R. A. (2017). Inviting uncertainty into the classroom. Educational Leadership, 75(2), $20-25$.

Benson, B., Burke, A. \& Carraccio, C. (2015) 'The Pediatrics Milestones project. A joint initiative of the Accreditation Council for Graduate Medical Education and the American Board of Pediatrics'.

Bentwich, M. E., \& Gilbey, P. (2017). More than visual literacy: Art and the enhancement of tolerance for ambiguity and empathy. BMC Medical Education, 17(1), 200.

Beresford, E. B. (1991). Uncertainty and the shaping of medical decisions. Hastings Center Report, 21(4), 6-11.

Berkhof, M., van Rijssen, H. J., Schellart, A. J., Anema, J. R., \& van der Beek, A. J. (2011). Effective training strategies for teaching communication skills to physicians: An overview of systematic reviews. Patient Education and Counseling, 84(2), 152-162.

Biley, F. C., \& Smith, K. L. (1999). Making sense of problem-based learning: The perceptions and experiences of undergraduate nursing students. Journal of Advanced Nursing, 30(5), 1205-1212.

Bingyou, R. G. (1991). Changes in students attitudes and values during medicine versus surgery clerkships. Medical Education, 25(5), 383-388. https://doi.org/10.1111/j.1365-2923.1991.tb00085.x.

Bintley, H. L., Bell, A., \& Ashworth, R. (2019). Remember to breathe: teaching respiratory physiology in a clinical context using simulation. Advances in Physiology Education, 43(1), 76-81.

Bleakley, A., \& Marshall, R. (2013). Can the science of communication inform the art of the medical humanities? Medical education, 47(2), 126-133.

Bovier, P. A., \& Perneger, T. V. (2007). Stress from uncertainty from graduation to retirement-A population-based study of Swiss physicians. Journal of General Internal Medicine, 22(5), 632-638.

Braun, V., \& Clarke, V. (2013). Successful qualitative research: A practical guide for beginners. London: Sage.

Brondani, M., \& Donnelly, L. (2020). COVID-19 pandemic: Students' perspectives on dental geriatric care and education. Journal of Dental Education, 84(11), 1237-1244.

Buljac-Samardzic, M., Dekker-van Doorn, C. M., van Wijngaarden, J. D., \& van Wijk, K. P. (2010). Interventions to improve team effectiveness: A systematic review. Health Policy, 94(3), 183-195.

Carleton, R. N. (2016). Into the unknown: A review and synthesis of contemporary models involving uncertainty. Journal of Anxiety Disorders, 39, 30-43.

Carr, S. M., Bell, B., Pearson, P. H., \& Watson, D. W. (2001). To be sure or not to be sure: concepts of uncertainty and risk in the construction of community nursing practice. Primary Health Care Research and Development, 2(4), 223-233.

Caulfield, M., Andolsek, K., Grbic, D., \& Roskovensky, L. (2014). Ambiguity tolerance of students matriculating to US medical schools. Academic medicine, 89(11), 1526-1532.

Chan, E. A., \& Nyback, M. H. (2015). A virtual caravan-A metaphor for home-internationalization through social media: A qualitative content analysis. Nurse Education Today, 35(6), 828-832. https://doi.org/10.1016/j.nedt.2015.01.024 (Epub 2015 Feb 14).

Coles, C. (2013). Learning about uncertainty in professional practice. In L. Sommers \& J. Launer (Eds.), Clinical uncertainty in primary care (pp. 47-69). New York: Springer.

Ironside, P.M., Jeffries, P.R. and Martin, A., 2009. Fostering patient safety competencies using multiplepatient simulation experiences. Nursing outlook, 57(6), pp.332-337.

Cooke, S., \& Lemay, J.-F. (2017). Transforming medical assessment: integrating uncertainty into the evaluation of clinical reasoning in medical education. Academic Medicine, 92(6), 746-751.

Cranley, L. A., Doran, D. M., Tourangeau, A. E., Kushniruk, A., \& Nagle, L. (2012). Recognizing and responding to uncertainty: A grounded theory of nurses' uncertainty. Worldviews on EvidenceBased Nursing, 9(3), 149-158.

Curtis, K. (2014). Learning the requirements for compassionate practice: student vulnerability and courage. Nurs Ethics., 21(2), 210-223. https://doi.org/10.1177/0969733013478307 (Epub 2013 Mar 20).

Curtis, K., Horton, K., \& Smith, P. (2012). Student nurse socialisation in compassionate practice: a Grounded Theory study. Nurse Education Today, 32(7), 790-795. https://doi.org/10.1016/j. nedt.2012.04.012 (Epub 2012 May 13). 
DeForge, B. R., \& Sobal, J. (1989). Intolerance of ambiguity in students entering medical school. Social Science and Medicine, 28(8), 869-874. https://doi.org/10.1016/0277-9536(89)90117-2.

Dodgson, J. E., Yahiro, M., Melby, C. S., Takeo, K., Tanaka, T., et al. (2018). Transformative elements of intercultural education for Japanese nursing students. Nursing and Health Sciences, 20(3), 323330. https://doi.org/10.1111/nhs.12567.

Domen, R. E. (2016). The ethics of ambiguity: Rethinking the role and importance of uncertainty in medical education and practice. Academic Pathology, 3, 2374289516654712.

Drummond, I., Sheikh, G., Skinner, J., \& Wood, M. (2016). Exploring the feasibility and acceptability of using tactical decision games to develop final year medical students' non-technical skills. Medical Teacher, 38(5), 510-514. https://doi.org/10.3109/0142159X.2016.1150979 (Epub 2016 Mar 23).

Duvivier, R., Stalmeijer, R., van Dalen, J., van der Vleuten, C., \& Scherpbier, A. (2014). Preliminary development and validation of the Supervisee Attachment Strategies Scale (SASS). BMC Medical Education, 14, 61 .

Eley, D. S., Leung, J. K., Campbell, N., \& Cloninger, C. R. (2017). Tolerance of ambiguity, perfectionism and resilience are associated with personality profiles of medical students oriented to rural practice. Medical Teacher, 39(5), 512-519.

Evans, L., Trotter, D. R., Jones, B. G., Ragain, R. M., Cook, R. L., et al. (2012). Epistemology and uncertainty. Family Medicine, 44(1), 14-21.

Fagundes, E. D., Ibiapina, C. C., Alvim, C. G., Fernandes, R. A., Carvalho-Filho, M. A., \& Brand, P. L. (2020). Case presentation methods: A randomized controlled trial of the one-minute preceptor versus SNAPPS in a controlled setting. Perspectives on Medical Education, 9(4), 245.

Fernandez, N., Foucault, A., Dube, S., Robert, D., Lafond, C., et al. (2016). Learning-by-Concordance $(\mathrm{LbC})$ : Introducing undergraduate students to the complexity and uncertainty of clinical practice. Canadian Medical Education Journal, 7(2), e104-e113.

Fielding, S. L. (1999). The practice of uncertainty: Voices of physicians and patients in medical malpractice claims. Greenwood: Praeger.

Finnerty, G., \& Pope, R. (2005). An exploration of student midwives' language to describe non-formal learning in professional practice. Nurse Education Today, 25(4), 309-315. https://doi.org/10.1016/j. nedt.2005.02.001 (Epub 2005 Apr 20).

Fox, R. C. (1957). Training for uncertainty. The student physician (pp. 207-241). Harvard: Harvard University Press.

Frambach, J. M., Driessen, E. W., Chan, L. C., \& van der Vleuten, C. P. M. (2012). Rethinking the globalisation of problem-based learning: How culture challenges self-directed learning. Medical Education, 46(8), 738-747. https://doi.org/10.1111/j.1365-2923.2012.04290.x.

Friary, P., Tolich, J., Morgan, J., Stewart, J., Gaeta, H., et al. (2018). Navigating interprofessional spaces: experiences of clients living with parkinson's disease, students and clinical educators. Journal of Interprofessional Care, 32(3), 304-312. https://doi.org/10.1080/13561820.2017.1417238.

Ganesh, A., \& Ganesh, G. (2010). Reflective writing by final year medical students: Lessons for curricular change. National Medical Journal of India, 23(4), 226-230.

Gärtner, J., Berberat, P. O., Kadmon, M., \& Harendza, S. (2020). Implicit expression of uncertainty-Suggestion of an empirically derived framework. BMC Medical Education, 20(1), 1-8.

Gaufberg, E., Dunham, L., Krupat, E., Stansfield, B., Christianson, C., et al. (2018). Do gold humanism honor society inductees differ from their peers in empathy, patient-centeredness, tolerance of ambiguity, coping style, and perception of the learning environment? Teaching and Learning in Medicine, 30(3), 284-293. https://doi.org/10.1080/10401334.2017.1419873.

Geller, G., Faden, R. R., \& Levine, D. M. (1990). Tolerance for ambiguity among medical-students-Implications for their selection, training and practice. Social Science and Medicine, 31(5), 619-624. https:// doi.org/10.1016/0277-9536(90)90098-d.

George, R. E., \& Lowe, W. A. (2019). Well-being and uncertainty in health care practice. The Clinical Teacher, 16(4), 298-305.

Gibson, K. R., Qureshi, Z. U., Ross, M. T., \& Maxwell, S. R. (2014). Junior doctor-led “near-peer" prescribing education for medical students. British Journal of Clinical Pharmacology, 77(1), 122-129. https ://doi.org/10.1111/bcp.12147.

GMC (2018) 'Outcomes for graduates '. Available at: https://www.gmc-uk.org/-/media/documents/dc113 26-outcomes-for-graduates-2018_pdf-75040796.pdf.

Gonzalo, J. D., Davis, C., Thompson, B. M., \& Haidet, P. (2020). Unpacking medical students' mixed engagement in health systems science education. Teaching and Learning in Medicine, 32(3), 250-8.

Gordon, G. H., Joos, S. K., \& Byrne, J. (2000). Physician expressions of uncertainty during patient encounters. Patient Education and Counseling, 40(1), 59-65. 
Gormley, G. J., \& Fenwick, T. (2016). Learning to manage complexity through simulation: Students' challenges and possible strategies. Perspectives on Medical Education, 5(3), 138-146. https://doi. org/10.1007/s40037-016-0275-3.

Gowda, D., Dubroff, R., Willieme, A., Swan-Sein, A., \& Capello, C. (2018). Art as sanctuary: A four-year mixed-methods evaluation of a visual art course addressing uncertainty through reflection. Academic Medicine, 93(11S), S8-S13.

Grenier, S., Barrette, A.-M., \& Ladouceur, R. (2005). Intolerance of uncertainty and intolerance of ambiguity: Similarities and differences. Personality and Individual Differences, 39(3), 593-600.

Groot, F., Jonker, G., Rinia, M., Ten Cate, O., \& Hoff, R. G. (2020). Simulation at the frontier of the zone of proximal development: A test in acute care for inexperienced learners. Academic Medicine, 79(3), 219-228.

Hammond, J. A., Hancock, J., Martin, M. S., Jamieson, S., \& Mellor, D. J. (2017). Development of a new scale to measure ambiguity tolerance in veterinary students. Journal of Veterinary Medical Education, 44(1), 38-49. https://doi.org/10.3138/jvme.0216-040R.

Han, P. K. J., Joekes, K., Elwyn, G., Mazor, K. M., Thomson, R., et al. (2014). Development and evaluation of a risk communication curriculum for medical students. Patient Education and Counseling, 94(1), 43-49. https://doi.org/10.1016/j.pec.2013.09.009.

Han, P. K., Klein, W. M., \& Arora, N. K. (2011). Varieties of uncertainty in health care: A conceptual taxonomy. Medical Decision Making, 31(6), 828-838.

Han, P. K. J., Schupack, D., Daggett, S., Holt, C. T., \& Strout, T. D. (2015). Temporal changes in tolerance of uncertainty among medical students: Insights from an exploratory study. Medical Education Online. https://doi.org/10.3402/meo.v20.28285.

Hancock, J., Hammond, J. A., Roberts, M., \& Mattick, K. (2017). Comparing tolerance of ambiguity in veterinary and medical students. Journal of Veterinary Medical Education, 44(3), 523-530. https://doi. org/10.3138/jvme.0916-150R1.

Handwerker, S. M. (2018). Challenges experienced by nursing students overcoming one course failure: A phenomenological research study. Teaching and Learning in Nursing, 13(3), 168-173. https://doi. org/10.1016/j.teln.2018.03.007.

Hayward, J., Cheung, A., Velji, A., Altarejos, J., Gill, P., et al. (2016). Script-theory virtual case: A novel tool for education and research. Medical Teacher, 38(11), 1130-1138. https://doi.org/10.3109/01421 59x.2016.1170776.

Hazel, S. J., Heberle, N., McEwen, M. M., \& Adams, K. (2013). Team-based learning increases active engagement and enhances development of teamwork and communication skills in a first-year course for veterinary and animal science undergraduates. Journal of Veterinary Medical Education, 40(4), 333-341. https://doi.org/10.3138/jvme.0213-034R1.

He, B., Prasad, S., Higashi, R. T., \& Goff, H. W. (2019). The art of observation: A qualitative analysis of medical students' experiences. BMC medical Education, 19(1), 234.

Helmich, E., Diachun, L., Joseph, R., LaDonna, K., Noeverman-Poel, N., et al. (2018). "Oh my God, I can't handle this!': trainees' emotional responses to complex situations." Medical Education, 52(2), 206-215. https://doi.org/10.1111/medu.13472.

Hillen, M. A., Gutheil, C. M., Strout, T. D., Smets, E. M., \& Han, P. K. (2017). Tolerance of uncertainty: conceptual analysis, integrative model, and implications for healthcare. Social Science and Medicine, $180,62-75$

Huijer, M., van Leeuwen, E., Boenink, A., \& Kimsma, G. (2000). Medical students' cases as an empirical basis for teaching clinical ethics. Academic Medicine, 75(8), 834-839.

Iannello, P., Mottini, A., Tirelli, S., Riva, S., \& Antonietti, A. (2017). Ambiguity and uncertainty tolerance, need for cognition, and their association with stress. A study among Italian practicing physicians. Medical Education, 22(1), 1270009.

Ilgen, J. S., Eva, K. W., de Bruin, A., Cook, D. A., \& Regehr, G. (2019). Comfort with uncertainty: reframing our conceptions of how clinicians navigate complex clinical situations. Advances in Health Sciences Education, 24(4), 797-809.

Ingvarsson, E., Verho, J., \& Rosengren, K. (2019). Managing uncertainty in nursing-newly gradu-ated nurses' experiences of introduction to the nursing profession. International Archives of Nursing and Health Care, 5, 119.

Ion, R., Smith, K., Nimmo, S., Rice, A. M., \& McMillan, L. (2015). Factors influencing student nurse decisions to report poor practice witnessed while on placement. Nurse in Education Today, 35(7), 900-915.

Ironside, P. M. (2003). New pedagogies for teaching thinking: the lived experiences of students and teachers enacting narrative pedagogy. Journal of Nurse Education, 42(11), 509-516. 
Ironside, P. M., Jeffries, P. R., \& Martin, A. (2009). Fostering patient safety competencies using multiplepatient simulation experiences. Nursing Outlook, 57(6), 332-337.

Johnsen, H. (2016). Learning to create new solutions together: A focus group study exploring interprofessional innovation in midwifery education. Nurse Education in Practice, 16(1), 298-304.

Johnson, C. G., Levenkron, J. C., Suchman, A. L., \& Manchester, R. (1988). Does physician uncertainty affect patient satisfaction? Journal of General Internal Medicine, 3(2), 144-149.

Jowsey, T., Petersen, L., Mysko, C., Cooper-Ioelu, P., Herbst, P., Webster, C. S., et al. (2020). Performativity, identity formation and professionalism: Ethnographic research to explore student experiences of clinical simulation training. Plos One, 15(7), e0236085.

Kashbour, W. A., Kendall, J., \& Grey, N. (2019). Students' perspectives of early and gradual transitioning between simulation and clinical training in dentistry and their suggestions for future course improvements. European Journal of Dental Education, 23(4), 471-481.

Katz, J. (1984). Why doctors don't disclose uncertainty. Hastings Center Report, 14(1), 35-44.

Klugman, C. M., Peel, J., \& Beckmann-Mendez, D. (2011). Art Rounds: Teaching interprofessional students visual thinking strategies at one school. Academic Medicine, 86(10), 1266-1271.

Koh, G. C. H., Khoo, H. E., Wong, M. L., \& Koh, D. (2008). The effects of problem-based learning during medical school on physician competency: A systematic review. Canadian Medical Association Journal, 178(1), 34-41. https://doi.org/10.1503/cmaj.070565.

Koufidis, C., Manninen, K., Nieminen, J., Wohlin, M., \& Silé, C. (2020). Grounding judgment in context: A conceptual learning model of clinical reasoning. Medical Education, 54(11), 1019-1028.

Kristiansson, M. H., Troein, M., \& Brorsson, A. (2014). We lived and breathed medicine-Then life catches up: Medical students' reflections. BMC Medical Education. https://doi.org/10.1186/1472-6920-14-66.

Krupat, E., Pelletier, S. R., \& Chernicky, D. W. (2011). The third year in the first person: medical students report on their principal clinical year. Academic Medicine, 86(1), 90-97. https://doi.org/10.1097/ ACM.0b013e3181ff9508.

Lally, J., \& Cantillon, P. (2014). Uncertainty and ambiguity and their association with psychological distress in medical students. Academic Psychiatry, 38(3), 339-344.

Landeen, J., Jewiss, T., Vajoczki, S., \& Vine, M. (2013). Exploring consistency within a problem-based learning context: Perceptions of students and faculty. Nurse Education in Practice, 13(4), 277-282.

Ledford, C. J., Seehusen, D. A., Chessman, A. W., \& Shokar, N. K. (2015). How we teach us medical students to negotiate uncertainty in clinical care. Family Medicine, 47(1), 31-36.

Leh, S. K. (2011). Nursing students' preconceptions of the community health clinical experience: implications for nursing education. Journal of Nursing Education, 50(11), 620-627. https://doi. org/10.3928/01484834-20110729-01.

Lemmon, M. E., Gamaldo, C., Salas, R. M. E., Saxena, A., Cruz, T. E., et al. (2018). Education research: Difficult conversations in neurology: Lessons learned from medical students. Neurology, 90(2), 93-97. https://doi.org/10.1212/wnl.0000000000004794.

Lewinson, L. P., McSherry, W., \& Kevern, P. (2018). "Enablement”spirituality engagement in pre-registration nurse education and practice: a grounded theory investigation. Religions, 9(11), 356. https://doi. org/10.3390/re19110356.

Light, D., Jr. (1979). Uncertainty and control in professional training. Journal of Health and Social Behavior, 20(4), 310-322.

Lingard, L., Garwood, K., Schryer, C. F., \& Spafford, M. M. (2003a). A certain art of uncertainty: Case presentation and the development of professional identity. Social Science and Medicine, 56(3), 603-616.

Lingard, L., Schryer, C., Garwood, K., \& Spafford, M. (2003). "Talking the talk": School and workplace genre tension in clerkship case presentations. Medical Education, 37(7), 612-620.

Liou, K. T., Jamorabo, D. S., Geha, R. M., Crawford, C. M., George, P., \& Schiffman, F. J. (2019). Foreign bodies: Is it feasible to develop tolerance for ambiguity among medical students through EquineFacilitated learning? Medical Teacher, 41(8), 960-2.

Llapa Rodrigues, E. O., Almeida Marques, D., Lopes Neto, D., Lopez Montesinos, M. J., \& Amado de Oliveira, A. S. (2016). Stressful situations and factors in students of nursing in clinical practice. Investigacion y Educacion en Enfermeria, 34(1), 211-220. https://doi.org/10.17533/udea.iee.v34n1a23.

Lo, L., \& Regehr, G. (2017). Medical students' understanding of directed questioning by their clinical preceptors. Teaching and Learning in Medicine, 29(1), 5-12.

Lodewyk, K., Linkiewich, D., Lee, A., \& Babenko, O. (2020). From Jerseys to Scrubs: Is sport background associated with medical students' tolerance of ambiguity and uncertainty? Health Professions Education, 6(4), 501-505.

Lodge, J. M., Kennedy, G., Lockyer, L., Arguel, A., \& Pachman, M. (2018). Understanding difficulties and resulting confusion in learning: An integrative review. Frontiers in Education, 3, 49. 
Logan, R., \& Scott, P. (1996). Uncertainty in clinical practice: implications for quality and costs of health care. The Lancet, 347(9001), 595-598.

Ludmerer, K. M. (1999). Time to heal: American medical education from the turn of the century to the era of managed care. Oxford: Oxford University Press.

Maguire, P. (1990). Can communication skills be taught? British Journal of Hospital Medicine, 43(3), 215-216.

Mangione, S., Chakraborti, C., Staltari, G., Harrison, R., Tunkel, A. R., et al. (2018). Medical students' exposure to the humanities correlates with positive personal qualities and reduced burnout: A multiinstitutional U.S. survey. Journal of General Internal Medicine, 33(5), 628-634.

Markey, K., Tilki, M., \& Taylor, G. (2018). Understanding nurses' concerns when caring for patients from diverse cultural and ethnic backgrounds. Journal of Clinical Nursing, 27(1/2), e259-e268. https://doi. org/10.1111/jocn.13926.

Markey, K., Tilki, M., \& Taylor, G. (2019). Resigned indifference: an explanation of gaps in care for culturally and linguistically diverse patients'. Journal of Nursing Management, 27(7), 1462-1470.

Martinez, W., \& Lo, B. (2008). Medical students' experiences with medical errors: An analysis of medical student essays. Medical Education, 42(7), 733-741.

Matchim, Y., \& Raetong, P. (2018). Thai nursing students' experiences of caring for patients at the end of life: a phenomenological study. International Journal of Palliative Nursing, 24(5), 220-229.

Maudsley, G., Williams, E. M., \& Taylor, D. C. (2008). Problem-based learning at the receiving end: a "mixed methods" study of junior medical students' perspectives. Adv Health Sci Educ Theory Pract., 13(4), 435-451. https://doi.org/10.1007/s10459-006-9056-9 (Epub 2007 Feb 7).

McCarthy, J., Graham, M. M., Tuohy, D., O’Brien, B., Fahy, A., et al. (2018). Potential and challenges for learning during acute medical/surgical placement for intellectual disability, mental health and midwifery students. Nurse Education in Practice, 28, 135-140.

McGaghie, W. C. (2018). Evaluation apprehension and impression management in clinical medical education. Academic Medicine, 93(5), 685-686.

Merrill, J., Camacho, Z., Laux, L., Lorimor, R., Thornby, J., et al. (1994). Uncertainties and ambiguities: Measuring how medical students cope. Medical Education, 28(4), 316-322.

Mishel, M. H. (1984). Perceived uncertainty and stress in illness. Research in Nursing and Health, 7(3), $163-171$.

Mol, S. S., Chen, H. C., Steerneman, A. H., de Groot, E., \& Zwart, D. L. (2019). The feasibility of longitudinal patient contacts in a large medical school. Teaching and Learning in Medicine, 31(2), 178-85.

Morton, K. R., Worthley, J. S., Nitch, S. R., Lamberton, H. H., Loo, L. K., et al. (2000). Integration of cognition and emotion: A postformal operations model of physician-patient interaction. Journal of Adult Development, 7(3), 151-160. https://doi.org/10.1023/a:1009542229631.

Munn, Z., Peters, M. D., Stern, C., Tufanaru, C., McArthur, A., et al. (2018). Systematic review or scoping review? Guidance for authors when choosing between a systematic or scoping review approach. $B M C$ Medical Research Methodology, 18(1), 143.

Mushtaq, F., Bland, A. R., \& Schaefer, A. (2011). Uncertainty and cognitive control. Frontiers in Psychology, 2, 249.

Nevalainen, M., Kuikka, L., Sjoberg, L., Eriksson, J., \& Pitkala, K. (2012). Tolerance of uncertainty and fears of making mistakes among fifth-year medical students. Family Medicine, 44(4), 240-246.

Nevalainen, M. K., Mantyranta, T., \& Pitkala, K. H. (2010). Facing uncertainty as a medical studentA qualitative study of their reflective learning diaries and writings on specific themes during the first clinical year. Patient Education and Counseling, 78(2), 218-223. https://doi.org/10.1016/j. pec.2009.07.011.

Neve, H., Lloyd, H., \& Collett, T. (2017). Understanding students' experiences of professionalism learning: A "threshold" approach." Teaching in Higher Education, 22(1), 92-108. https://doi. org/10.1080/13562517.2016.1221810.

Nguyen, M., Miranda, J., Lapum, J., \& Donald, F. (2016). Arts-based learning: A new approach to nursing education using andragogy. Journal of Nursing Education, 55(7), 407-410. https://doi. org/10.3928/01484834-20160615-10.

Nixon, J., Wolpaw, T., Schwartz, A., Duffy, B., Menk, J., et al. (2014). SNAPPS-Plus: an educational prescription for students to facilitate formulating and answering clinical questions (Evaluation Studies). Academic Medicine, 89(8), 1174-1179. https://doi.org/10.1097/ACM.0000000000000362.

Ofri, D. (2017). Medical humanities: The Rx for uncertainty? Academic Medicine, 92(12), 1657-1658.

Overoye, A. L., \& Storm, B. C. (2015). Harnessing the power of uncertainty to enhance learning. Translational Issues in Psychological Science, 1(2), 140.

Patel, P., Martimianakis, M. A., Zilbert, N. R., Mui, C., Mobilio, M. H., et al. (2018). Fake it'til you make it: Pressures to measure up in surgical training. Academic Medicine, 93(5), 769-774. 
Penrod, J. (2001). Refinement of the concept of uncertainty. Journal of Advanced Nursing, 34(2), $238-245$.

Peters, M. D., Godfrey, C. M., Khalil, H., McInerney, P., Parker, D., et al. (2015). Guidance for conducting systematic scoping reviews. International Journal of Evidence-Based Healthcare, 13(3), 141-146.

Porteous, D. J., \& Machin, A. (2018). The lived experience of first year undergraduate student nurses: A hermeneutic phenomenological study. Nurse Education Today, 60, 56-61. https://doi.org/10.1016/j. nedt.2017.09.017.

Ramos-Morcillo, A. J., Leal-Costa, C., Moral-García, J. E., \& Ruzafa-Martínez, M. (2020). Experiences of nursing students during the abrupt change from face-to-face to E-learning education during the first month of confinement due to COVID-19 in Spain. International Journal of Environmental Research and Public Health, 17(15), 5519.

RCVS (2018). Graduate Outcomes Consultation (November 2018). Retrieved from https://www.rcvs.org.uk/ news-and-views/publications/graduate-outcomes-consultation/

Klugman, C. M., Peel, J., \& Beckmann-Mendez, D. (2011). Art rounds: Teaching interprofessional students visual thinking strategies at one school. Academic Medicine, 86(10), 1266-1271.

Warner, T. D., Roberts, L. W., Smithpeter, M., Rogers, M., Roberts, B., McCarty, T., et al. (2001). Uncertainty and opposition of medical students toward assisted death practices. Journal of Pain and Symptom Management, 22(2), 657-667.

Riegelman, R. K., Povar, G. J., \& Ott, J. E. (1983). Medical students' skills, attitudes, and behavior needed for literature reading. Journal of Medical Education, 58(5), 411-417.

Rosen, N. O., Ivanova, E., \& Knäuper, B. (2014). Differentiating intolerance of uncertainty from three related but distinct constructs. Anxiety, Stress and Coping, 27(1), 55-73.

Rowan, C. J., McCourt, C., \& Beake, S. (2008). Problem based learning in midwifery-The students' perspective. Nurse Education Today, 28(1), 93-99.

Sawanyawisuth, K., Schwartz, A., Wolpaw, T., \& Bordage, G. (2015). Expressing clinical reasoning and uncertainties during a Thai internal medicine ambulatory care rotation: Does the SNAPPS technique generalize? Medical Teacher, 37(4), 379-384. https://doi.org/10.3109/0142159x.2014.947942.

Schéle, I., Hedman, L., \& Hammarström, A. (2011). Shared ambiguity but different experiences and demands among dental students-A gender perspective. Qualitative Research in Psychology, 8(1), 1-25. https://doi.org/10.1080/14780880902874231.

Scott, A., Sudlow, M., Shaw, E., \& Fisher, J. (2020). Medical education, simulation and uncertainty. The Clinical Teacher, 17(5), 497-502.

Senette, L., O'Malley, M., \& Hendrix, T. (2013). Passing the baton: using simulation to develop student collaboration. Clinical Simulation in Nursing, 9(2), E39-E46. https://doi.org/10.1016/j. ecns.2011.08.005.

Shihata, S., McEvoy, P. M., Mullan, B. A., \& Carleton, R. N. (2016). Intolerance of uncertainty in emotional disorders: What uncertainties remain? Journal of Anxiety Disorders, 41, 115-124.

Simpkin, A. L., Khan, A., West, D. C., Garcia, B. M., Sectish, T. C., et al. (2018). Stress from uncertainty and resilience among depressed and burned out residents: A cross-sectional study. Academic pediatrics, 18(6), 698-704.

Simpkin, A. L., \& Schwartzstein, R. M. (2016). Tolerating uncertainty-The next medical revolution? New England Journal of Medicine, 375(18), 1713-1718.

Sobal, J., \& Deforge, B. R. (1991). Medical uncertainty in students entering medical-school. Sociological Focus, 24(4), 291-301. https://doi.org/10.1080/00380237.1991.10570596.

Sommers, L. S., \& Launer, J. (2014). Clinical uncertainty in primary care. NewYork: Springer.

Steinauer, J. E., O’Sullivan, P., Preskill, F., ten Cate, O., \& Teherani, A. (2018). What makes "difficult patients" difficult for medical students? Academic Medicine, 93(9), 1359-1366. https://doi. org/10.1097/acm.0000000000002269.

Stephens, G. C., Rees, C. E., Lazarus, M., \& D. . (2020). Exploring the impact of education on preclinical medical students' tolerance of uncertainty: A qualitative longitudinal study. Advances in Health Sciences Education. https://doi.org/10.1007/s10459-020-09971-0.

Stone, J. P., Charette, J. H., McPhalen, D. F., \& Temple-Oberle, C. (2015). Under the knife: Medical student perceptions of intimidation and mistreatment. Journal of Surgical Education, 72(4), 749-753. https:// doi.org/10.1016/j.jsurg.2015.02.003.

Strout, T. D., Hillen, M., Gutheil, C., Anderson, E., Hutchinson, R., et al. (2018). Tolerance of uncertainty: A systematic review of health and healthcare-related outcomes. Patient Education and Counseling, 101(9), 1518-1537.

Teunissen, P. W., \& Westerman, M. (2011). Opportunity or threat: the ambiguity of the consequences of transitions in medical education. Medical Education, 45(1), 51-59. 
Toivonen, A. K., Lindblom-Ylanne, S., Louhiala, P., \& Pyorala, E. (2017). Medical students' reflections on emotions concerning breaking bad news. Patient Education and Counseling, 100(10), 1903-1909. https://doi.org/10.1016/j.pec.2017.05.036.

Tonelli, M. R., \& Upshur, R. E. (2019). A philosophical approach to addressing uncertainty in medical education. Academic Medicine, 94(4), 507-511.

Tricco, A. C., Lillie, E., Zarin, W., O’Brien, K. K., Colquhoun, H., et al. (2018). PRISMA extension for scoping reviews (PRISMA-ScR): Checklist and explanation. Annals of Internal Medicine, 169(7), $467-473$.

Uygur, J., Stuart, E., De Paor, M., Wallace, E., Duffy, S., et al. (2019). A Best Evidence in Medical Education systematic review to determine the most effective teaching methods that develop reflection in medical students. Medical Teacher, 41(1), 3-16.

Vae, K. J. U., Engstrom, M., Martensson, G., \& Lofmark, A. (2018). Nursing students' and preceptors' experience of assessment during clinical practice: A multilevel repeated-interview study of studentpreceptor dyads. Nurse Education in Practice, 30, 13-19. https://doi.org/10.1016/j.nepr.2017.11.014.

van Ryn, M., Hardeman, R. R., Phelan, S. M., Burke, S. E., Przedworski, J., et al. (2014). Psychosocial predictors of attitudes toward physician empathy in clinical encounters among 4732 1st year medical students: a report from the CHANGES study. Patient Education and Counselling, 96(3), 367-75.

Wald, H. S., Anthony, D., Hutchinson, T. A., Liben, S., Smilovitch, M., et al. (2015). Professional identity formation in medical education for humanistic, resilient physicians: pedagogic strategies for bridging theory to practice. Academic Medicine, 90(6), 753-760.

Warner, T. D., Roberts, L. W., Smithpeter, M., Rogers, M., Roberts, B., McCarty, T., et al. (2001). Uncertainty and opposition of medical students toward assisted death practices. Journal of Pain and Symptom Management, 22(2), 657-667.

Watkins, K. D., Roos, V., \& Van der Walt, E. (2011). An exploration of personal, relational and collective well-being in nursing students during their training at a tertiary education institution. Health $S A$ Gesondheid, 16(1), 1-10. https://doi.org/10.4102/hsag.v16i1.552.

Wayne, S., Dellmore, D., Serna, L., Jerabek, R., Timm, C., et al. (2011). The association between intolerance of ambiguity and decline in medical students' attitudes toward the underserved. Academic Medicine, 86(7), 877-882. https://doi.org/10.1097/ACM.0b013e31821dac01.

Wear, D. (2009). Perspective: A perfect storm: The convergence of bullet points, competencies, and screen reading in medical education. Academic Medicine, 84(11), 1500-1504.

Weurlander, M., Lönn, A., Seeberger, A., Hult, H., Thornberg, R., \& Wernerson, A. (2019). Emotional challenges of medical students generate feelings of uncertainty. Medical education., 53(10), 1037-48.

White, G., \& Williams, S. (2017). The certainty of uncertainty: can we teach a constructive response? Medical Education, 51(12), 1200-1202.

Wijnen-Meijer, M., Burdick, W., Alofs, L., Burgers, C., \& ten Cate, O. (2013). Stages and transitions in medical education around the world: clarifying structures and terminology. Medical teacher, 35(4), 301-307.

Wilkinson, T. J. (2017). Kolb, integration and the messiness of workplace learning. Perspectives on Medical Education, 6(3), 144-145.

Wolpaw, T., Côté, L., Papp, K. K., \& Bordage, G. (2012). Student uncertainties drive teaching during case presentations: more so with SNAPPS. Academic Medicine, 87(9), 1210-1217.

Wolpaw, T., Papp, K. K., \& Bordage, G. (2009). Using SNAPPS to facilitate the expression of clinical reasoning and uncertainties: a randomized comparison group trial. Academic Medicine, 84(4), 517-524.

Wray, C. M., \& Loo, L. K. (2015). The diagnosis, prognosis, and treatment of medical uncertainty. Journal of graduate medical education, 7(4), 523-527.

Young-Brice, A., Dreifuerst, K. T., \& Buseh, A. (2018). Being invisible: Stereotype threat in an undergraduate nursing program. Journal of Nursing Education, 57(3), 159-162. https://doi.org/10.3928/01484 834-20180221-06.

Publisher's Note Springer Nature remains neutral with regard to jurisdictional claims in published maps and institutional affiliations. 